\title{
Molecular mechanisms underlying the actions of arachidonic acid-derived prostaglandins on peripheral nociception
}

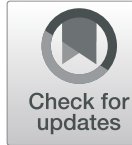

Yongwoo Jang ${ }^{1,2+}$, Minseok $\mathrm{Kim}^{3+}$ and Sun Wook Hwang ${ }^{3,4^{*}}$ (D)

\begin{abstract}
Arachidonic acid-derived prostaglandins not only contribute to the development of inflammation as intercellular pro-inflammatory mediators, but also promote the excitability of the peripheral somatosensory system, contributing to pain exacerbation. Peripheral tissues undergo many forms of diseases that are frequently accompanied by inflammation. The somatosensory nerves innervating the inflamed areas experience heightened excitability and generate and transmit pain signals. Extensive studies have been carried out to elucidate how prostaglandins play their roles for such signaling at the cellular and molecular levels. Here, we briefly summarize the roles of arachidonic acid-derived prostaglandins, focusing on four prostaglandins and one thromboxane, particularly in terms of their actions on afferent nociceptors. We discuss the biosynthesis of the prostaglandins, their specific action sites, the pathological alteration of the expression levels of related proteins, the neuronal outcomes of receptor stimulation, their correlation with behavioral nociception, and the pharmacological efficacy of their regulators. This overview will help to a better understanding of the pathological roles that prostaglandins play in the somatosensory system and to a finding of critical molecular contributors to normalizing pain.
\end{abstract}

Keywords: Inflammation, Prostaglandin, Pain, Signal transduction, DRG neuron

\section{Introduction}

Polyunsaturated fatty acids are oxygenated via cellular enzymatic processes [1]. Cyclooxygenase (COX, also known as prostaglandin $\mathrm{G} / \mathrm{H}$ synthase (PTGS\}), epoxygenase, and lipoxygenase catalyze those reactions [1]. The resulting oxygenated metabolites, termed eicosanoids, function as crucial bioactive lipids. Near or inside the peripheral somatosensory system, these eicosanoids play diverse roles in the proinflammatory, anti-inflammatory, and resolving phases of injury. During those phases, secreted eicosanoids often greatly alter the functions of neuronal components [2]. Arachidonic acid is a C20 polyunsaturated $\omega-6$ fatty acid. Among the arachidonic acid-derived eicosanoids, prostaglandin $\mathrm{G} 2\left(\mathrm{PGG}_{2}\right)$ and subsequently $\mathrm{H}_{2}\left(\mathrm{PGH}_{2}\right)$ are first generated by the actions of COX, and can then be further

\footnotetext{
* Correspondence: sunhwang@korea.ac.kr

${ }^{\dagger}$ Yongwoo Jang and Minseok Kim contributed equally to this work.

${ }^{3}$ Department of Biomedical Sciences, Korea University, Seoul 02841, South

Korea

${ }^{4}$ Department of Physiology, College of Medicine, Korea University, Seoul

02841, South Korea

Full list of author information is available at the end of the article
}

metabolized into $\mathrm{PGE}_{2}, \mathrm{PGD}_{2}, \mathrm{PGI}_{2}$, and $\mathrm{TXA}_{2}$ by a corresponding prostaglandin synthase (Fig. 1) [3]. $\mathrm{PGA}_{2}$ and $\mathrm{PGI}_{2}$ are formed by the dehydration of $\mathrm{PGE}_{2}$ and $\mathrm{D}_{2}$, respectively. In a paracrine or autocrine manner, most of these PGs preferentially recognize one or more receptors coupled to $G$ proteins expressed on the cell surface. That interaction then initiates intracellular signal transductions, including cyclic adenosine monophosphate (cAMP)- and calcium ion $\left(\mathrm{Ca}^{2+}\right)$-induced cascades, which can occur, among other places, in the neuronal components constituting somatosensory ganglia experiencing inflammation in or around themselves [4]. Many studies have revealed that the receptor-specific actions of PGs mostly heighten neuronal excitability, which can cause pro-nociceptive outcomes. In this review, we focus on the contribution of each specific PG action to pain signaling and construct systemic information to describe the molecular mechanisms that underlie their actions on the neurons of the somatosensory ganglia.

(C) The Author(s). 2020 Open Access This article is distributed under the terms of the Creative Commons Attribution 4.0 International License (http://creativecommons.org/licenses/by/4.0/), which permits unrestricted use, distribution, and reproduction in any medium, provided you give appropriate credit to the original author(s) and the source, provide a link to the Creative Commons license, and indicate if changes were made. The Creative Commons Public Domain Dedication waiver (http://creativecommons.org/publicdomain/zero/1.0/) applies to the data made available in this article, unless otherwise stated. 


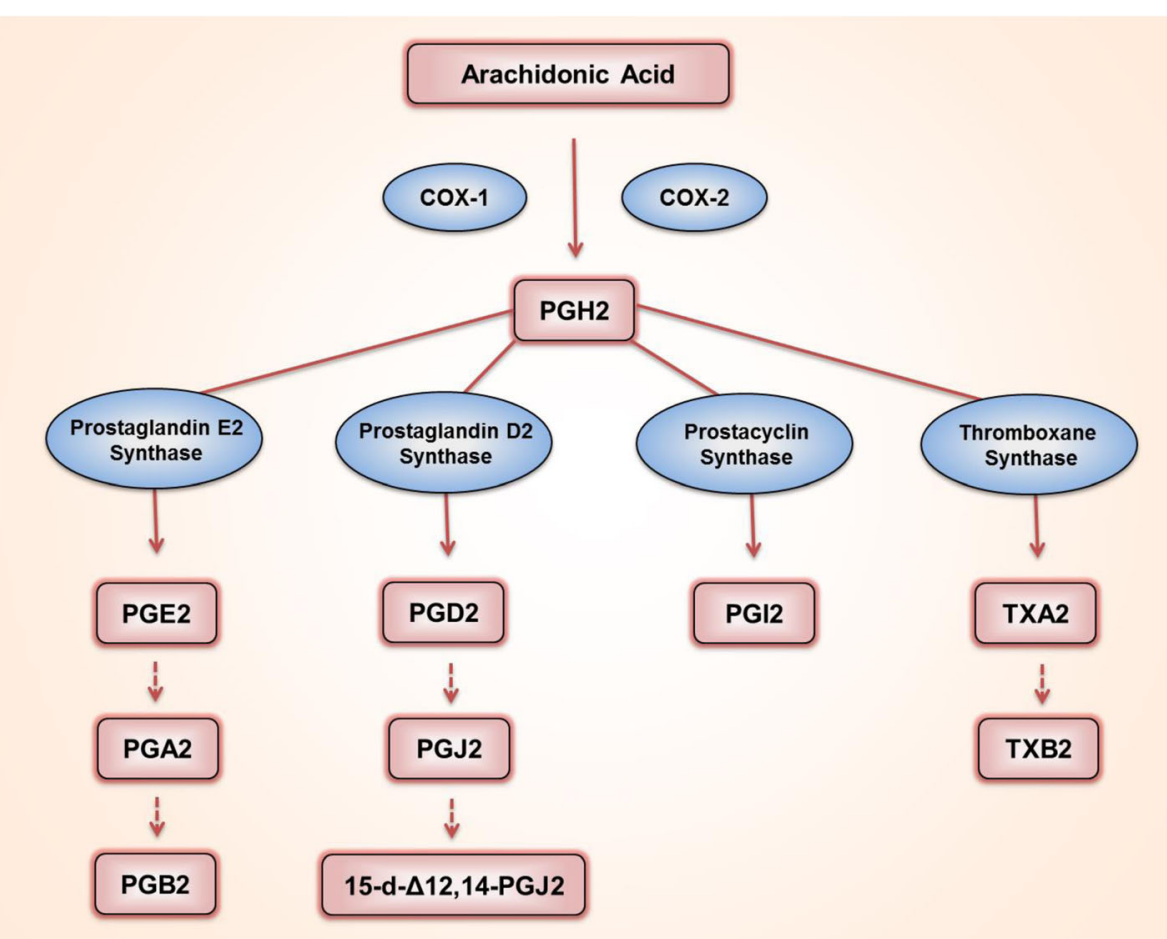

Fig. 1 Biosynthetic pathways of arachidonic acid-mediated prostaglandins (PGs). $\mathrm{PGH}_{2}$ is generated from arachidonic acid by enzymatic reactions of COX-1 or COX-2, and is further metabolized into $\mathrm{PGE}_{2}, \mathrm{PGD}_{2}, \mathrm{PG}_{2}$, or $\mathrm{TXA}_{2}$ by specific synthases. When dehydrated, $\mathrm{PGE}_{2}$ is converted into $P G A_{2}$ and $P G B_{2}$, and $P G D_{2}$ is converted into $P G J_{2}$. $P G J_{2}$ can further be isomerized into 15 -deoxy- $\Delta 12,14-P G J_{2}\left(15 d-P G J_{2}\right)$. TXA 2 is rapidly hydrolyzed into $\mathrm{TXB}_{2}$

\section{COX in the peripheral somatosensory system}

COX, the key element in the biosynthetic pathway of PGs, catalyzes the following serial reactions: the cyclooxygenation of arachidonic acid to $\mathrm{PGG}_{2}$ and a subsequent peroxidation that reduces $\mathrm{PGG}_{2}$ to $\mathrm{PGH}_{2}$ [3] (Fig. 1). In humans, COX has two isoforms, COX-1 and COX-2, and their expressions and functions are separately regulated in various tissues [5]. When inflamed, tissues and recruited inflammatory cells increase PG production and secretion, and the secreted PGs can stimulate the innervating neurons in a paracrine fashion [6]. In addition, the neuron itself also has the potential to generate PGs because it also expresses COX. In the dorsal root ganglia (DRG), which are collections of cell bodies of somatosensory neurons, and in the spinal cord, where DRG neurons form their first synapses, COX isoform expression that depends on physiological and inflammatory conditions has been investigated as follows.

\section{COX expression in the spinal cord and somatosensory neurons}

Spinal cord expression of COX-1 and COX-2 was first examined in 1996. Reverse transcription-polymerase chain reaction (RT-PCR) analyses showed that both of the Ptgs transcripts encoding COX-1 and -2 proteins were constitutively expressed in the rat spinal cord and that Ptgs2 was predominant [7]. Beiche et al. further demonstrated that peripheral inflammation induced by hind paw injection of complete Freund's adjuvant (CFA) up-regulated the lumbar spinal expression of Ptgs2 but not Ptgs1, which indicates that COX-2 is more important than COX-1 in that pathological state. Such spinal expressions have repeatedly been confirmed in multiple animal models [6, 8-12]. For example, an intraperitoneal injection of the endotoxin lipopolysaccharide (LPS) (1 $\mathrm{mg} / \mathrm{kg}$ ) in mice significantly elevated the levels of Ptgs 2 mRNA and COX-2 protein in the spinal cord, with no change in the levels of Ptgs1 or COX-1 protein [13]. Immunohistochemistry has later been employed to obtain lamina-specific information regarding COX-1 and -2 expression, because the synaptic transmission of nociceptive signals from nociceptor DRG neurons in response to noxious peripheral stimuli occurs in the superficial dorsal horn (laminae I and II). The result showed that the a normal spinal cord expressed the COX-1 isoform throughout the whole gray matter area, whereas COX-2 expression was relatively intense in laminae I and II, as well as around the central canal (lamina X) [14]. A comparison study using transgenic mice (wild-type mice and heterozygous and homozygous knockouts for the Ptgs 1 and Ptgs2 genes) confirmed the spinal expression of both enzymes [15]. Collectively, therefore, the COXs are 
commonly expressed in the spinal cord, and peripheral inflammation can preferentially lead to an increase in COX-2 expression (Table 1).

DRG neurons are presynaptic components in the spinal dorsal horn and are anatomically and functionally classified into four subpopulations: C-nociceptors, $\mathrm{A} \delta$ nociceptors, $\mathrm{A} \beta$ touch fibers, and $A \alpha$-proprioceptors. The unmyelinated $\mathrm{C}$ - and thinly myelinated $\mathrm{A} \delta$-fibers have relatively small-to-medium-sized cell bodies and axons and are essential for pain perception because they transduce potentially harmful stimuli such as noxious ranges of temperatures, damaging stretches, and painful substances into electrical signals [22, 23]. The thickly myelinated A-fibers (A $\alpha$ - and $A \beta$ - fibers) have relatively large somas and axons and are responsible for the transduction of innocuous mechanical stimuli [22, 23].

Comparisons of such subpopulations have reported differential COX expression levels. The COX-1 isoform has been detected in the cytosolic compartment and axonal processes of small-to-medium sized rat DRG neurons, but

Table 1 Expressions of COX-1 and COX-2 in dorsal root ganglia (DRG) and spinal cord

\begin{tabular}{|c|c|c|c|c|}
\hline DRG and/or spinal cord & COX isoforms & Animal models & Expression & References \\
\hline lumbar spinal cord & COX-2 mRNA & $\begin{array}{l}\text { Freund's adjuvant-induced } \\
\text { rat }\end{array}$ & Increase & {$[7]$} \\
\hline gray matter of the spinal cord & COX-1 protein & Normal rat & Detection & [14] \\
\hline $\begin{array}{l}\text { superficial dorsal horn of the spinal cord (laminae I and II) } \\
\text { Around the central canal (lamina X) }\end{array}$ & COX-2 protein & Normal rat & Detection & [14] \\
\hline small to medium sized $\left(<1000 \mu m^{2}\right)$ DRG & COX-1 protein & Normal rat & Detection & {$[14,16]$} \\
\hline DRG & COX-2 protein & Normal rat & No detection & {$[14,16]$} \\
\hline spinal cord & $\begin{array}{l}\text { COX-1, COX-2 } \\
\text { protein }\end{array}$ & $\begin{array}{l}\text { Kaolin and carrageenan- } \\
\text { induced arthritis rat }\end{array}$ & $\begin{array}{l}\text { No change in COX-1, in- } \\
\text { crease in COX-2 }\end{array}$ & {$[8]$} \\
\hline spinal cord & COX-1 mRNA & COX-2-deficient mice & Increase & {$[15]$} \\
\hline spinal cord & COX-2 mRNA & COX-1-deficient mice & No change & [15] \\
\hline part of COX-1-positive DRG neurons & COX-1 protein & $\begin{array}{l}\text { Freund's adjuvant-injected } \\
\text { rat }\end{array}$ & No change & [16] \\
\hline DRG & COX-2 protein & $\begin{array}{l}\text { Freund's adjuvant-injected } \\
\text { rat }\end{array}$ & No detection & [16] \\
\hline spinal cord & COX-2 protein & $\begin{array}{l}\text { Freund's adjuvant-injected } \\
\text { rat }\end{array}$ & Increase & [6] \\
\hline L4 and L5 DRG & COX-1 protein & COX-1/COX-2-deficient mice & No detection in COX-1 & {$[17]$} \\
\hline L4 and L5 DRG & COX-2 protein & COX-1/COX-2-deficient mice & No detection & {$[17]$} \\
\hline L4 and L5 DRG & $\begin{array}{l}\text { COX-1, COX-2 } \\
\text { protein }\end{array}$ & Normal mouse & No detection in COX-2 & {$[17]$} \\
\hline L4 - L6 DRG and spinal cord, & $\begin{array}{l}\text { COX-1, COX-2 } \\
\text { protein }\end{array}$ & Normal rat & Detection & [10] \\
\hline spinal cord & $\begin{array}{l}\text { COX-2 mRNA / } \\
\text { protein }\end{array}$ & $\begin{array}{l}\text { Formalin-induced inflamed } \\
\text { rat }\end{array}$ & $\begin{array}{l}\text { Increase in mRNA, no } \\
\text { change in protein }\end{array}$ & [9] \\
\hline L4 and L5 DRG & COX-1 mRNA & $\begin{array}{l}\text { Collagen-induced arthritis } \\
\text { mouse }\end{array}$ & No change & {$[17]$} \\
\hline L4 and L5 DRG & COX-2 mRNA & $\begin{array}{l}\text { Collagen-induced arthritis } \\
\text { mouse }\end{array}$ & No detection & {$[17]$} \\
\hline spinal cord & $\begin{array}{l}\text { COX-1 mRNA / } \\
\text { Protein }\end{array}$ & $\begin{array}{l}\text { LPS-induced inflamed } \\
\text { mouse }\end{array}$ & No change & [13] \\
\hline spinal cord & $\begin{array}{l}\text { COX-2 mRNA / } \\
\text { Protein }\end{array}$ & $\begin{array}{l}\text { LPS-induced inflamed } \\
\text { mouse }\end{array}$ & Increase & [13] \\
\hline spinal cord & $\begin{array}{l}\text { COX-2 mRNA / } \\
\text { protein }\end{array}$ & $\begin{array}{l}\text { LPS-induced inflamed } \\
\text { mouse }\end{array}$ & increase & {$[18]$} \\
\hline DRG and spinal cord & $\begin{array}{l}\text { COX-1, COX-2 } \\
\text { mRNA }\end{array}$ & $\begin{array}{l}\text { Carrageenen-induced } \\
\text { inflamed mouse }\end{array}$ & $\begin{array}{l}\text { No change in COX-1, In- } \\
\text { creaser in COX-2 }\end{array}$ & [19] \\
\hline L4 DRG & $\begin{array}{l}\text { COX-2 mRNA / } \\
\text { protein }\end{array}$ & $\begin{array}{l}\text { Freund's adjuvant-injected } \\
\text { rat }\end{array}$ & Increase & {$[20]$} \\
\hline TRPV1-positive cells in L5 DRG & $\begin{array}{l}\text { COX-1, COX-2 } \\
\text { protein }\end{array}$ & $\begin{array}{l}\text { IL-1 } \beta \text { - or carrageenan- } \\
\text { induced rat }\end{array}$ & Increase & {$[21]$} \\
\hline
\end{tabular}


COX-2 was not expressed in those neurons $[14,16]$. The same research group further detected COX-1 in $65 \%$ of calcitonin gene-related peptide (CGRP)-positive and 70\% of isolectin B4 (IB4)-positive DRG neurons, suggesting that the majority of both peptidergic and non-peptidergic small-diameter nociceptors express COX-1 [16]. Dou and colleagues confirmed the presence of COX-1 and absence of COX-2 in mouse lumbar (L4 and L5) DRG and further revealed the presence of a new variant of COX-1 containing intron-1 (referred to as COX-3, which is not expressed in humans) in those lumbar DRG [17]. Regarding COX-2 expression, they used a collagen-induced arthritis model and found that Ptgs 2 mRNA was increased in inflamed hind paw skin and the lumbar spinal cord, but remained absent in the L4 and L5 DRG [17]. Interestingly, recent studies have suggested that certain pathological states can cause COX-2 expression in DRG neurons. For example, carrageenan-induced peripheral inflammation elevated the Ptgs2 mRNA level in DRG neurons [19]. L4 periganglionic inflammation caused by the injection of CFA robustly induced COX-2 expression in the L4 DRG [20]. Araldi and colleagues also showed that epidermal administration of interleukin-1 $\beta$ (IL-1 $\beta$ ) or carrageenan to rat hind paws elevated COX-1 and COX-2 levels in the nociceptive ion channel transient receptor potential vanilloid subtype 1 (TRPV1)-positive DRG nociceptors in charge of the injected dermatome [21]. Therefore, PGs can be produced in nociceptor afferents in addition to their innervated areas when inflamed and possibly affect neuronal functions in autocrine and/or paracrine manners. According to this collective information on COX expression, both the pro-inflammatory enzymes COX-1 and COX-2 could be involved in the nociception that is exerted by peripheral somatosensory components, and COX-2 expression can be up-regulated upon inflammation.

\section{COX implication in pain from genetic approaches}

In pain behavioral tests using transgenic animals, heat nociception was reduced in Ptgs1-null mice, and chemical nociception in response to acetic acid was blunted in Ptgs1-deficient heterozygotes, Ptgs2-deficient female heterozygotes, and Ptgs1-null mice [15]. Despite the difficulties in interpreting these behavioral parameters because of the spinal increase in COX-1 seen in Ptgs 2 knockouts, which possibly resulted from a compensatory mechanism, those authors suggested that both of the COXs serve a role in pain development [15]. However, to further specify the peripheral contribution of individual COXs in the peripheral pain pathway, more systematic approaches might be required, such as using conditional deletions of Ptgs in the spinal cord or DRG neurons. In fact, a similar concept was recently attempted. Animals were generated to have tissuespecific knockdowns of Ptgs1 or Ptgs 2 by directly injecting antisense oligodeoxynucleotides (ODNs) in the L5 DRG, and both of the knockdown treatments prevented the hind paw hyperalgesia induced by IL- $1 \beta$ injection [21]. Therefore, the ascending neural pathway for pain signaling composed of the DRG and spinal cord expresses COX-1 and COX-2, and those two enzymes appear to contribute to nociceptive transduction.

\section{Pharmacological evidence for COX actions in nociceptors}

Pharmacological studies have shown that COX-mediated peripheral nociceptive mechanisms contribute to pain in various pathological models (Table 2 summarizes the COX selectivity of various pharmacological agents). Those can be subcategorized into three types of approaches: nociceptor-specific measures, peripherally localized treatment, and peripherally localized stimulation.

\section{Studies using nociceptor specific measures}

In an earlier study on the wind-up of a spinal nociceptive reflex in rats, systemic administration of the nonselective COX inhibitor indomethacin or the selective COX-2 inhibitor SC-58125 reduced the firing magnitude of C-nociceptors in a dose-dependent manner when evoked by electrical stimulation at a frequency of $0.5-$ $0.8 \mathrm{~Hz}$ [14]. In contrast, the intrathecal administration of the COX inhibitors indomethacin and meclofenamic acid failed to suppress the responses of spinal dorsal horn neurons to noxious mechanical stimulation at the ankle or knee joint [14].

CFA-induced periganglionic inflammation led to mechanical and thermal hyperalgesia of the relevant hind paw with increased COX-2 expression in DRG neurons, which was blunted by the subcutaneous administration of rofecoxib, a COX-2-specific inhibitor (1 mg/kg) [20].

Substance P (SP) is a peptidergic neurotransmitter released from a subset of C-fibers in the DRG [44]. Its release from the central ending in the dorsal horn strengthens the synaptic transmission of pain signals and its release from the peripheral terminal causes neurogenic inflammation [44]. In vitro stimulation of cultured DRG neurons with an inflammatory soup containing potassium chloride, thrombin, bradykinin (BK), and endothelin-1 led to increased neuronal transcription of preprotachykinin, which is an SP precursor, and increased SP release [26]. The COX inhibitors nimesulide and diclofenac and COX2 inhibitor celecoxib all deterred those SP induction processes [26]. Moreover, treating cultured DRG neurons with the COX inhibitors nimesulide and paracetamol suppressed the translocation of epsilon type protein kinase $\mathrm{C}(\mathrm{PKC \varepsilon})$ to the plasma membrane by thrombin and $\mathrm{BK}$, which is mentioned below as an essential axis for $\mathrm{PGE}_{2}$ downstream signaling [26]. The same study confirmed that both 
Table 2 COX inhibitors used in the experiments mentioned in this review

\begin{tabular}{|c|c|c|c|c|}
\hline Type & Name & Inhibitors & Notes (Molecular or cellular outcomes except reductions in PGs or pain) & References \\
\hline \multirow[t]{2}{*}{$\begin{array}{l}\text { Selective COX-1 } \\
\text { inhibitors }\end{array}$} & \multirow[t]{2}{*}{$\operatorname{cox}-1$} & $\begin{array}{l}\text { Valeryl } \\
\text { salicylate }\end{array}$ & $\downarrow \|$ L-1 $\beta$-induced hyperalgesia & {$[21]$} \\
\hline & & SC-560 & $\downarrow V E G F-i n d u c e d$ growth cone formation & $\begin{array}{l}{[9,10,24,} \\
25]\end{array}$ \\
\hline \multirow{8}{*}{$\begin{array}{l}\text { Selective COX-2 } \\
\text { inhibitors }\end{array}$} & \multirow[t]{8}{*}{$\operatorname{cox}-2$} & Celecoxib & $\downarrow$ substance $P, \downarrow T T X-R I_{N a}, \downarrow C G R P, \downarrow P 2 X 3$ expression & {$[9,26-28]$} \\
\hline & & Lumiracoxib & & [13] \\
\hline & & Meloxicam & $\downarrow$ neurogenesis & {$[29,30]$} \\
\hline & & Nimesulide & $\downarrow$ neurogenesis, $\downarrow$ substance $P, \downarrow P K C \varepsilon$ translocation & {$[26,30]$} \\
\hline & & NS-398 & $\downarrow \mathrm{BDNF}$ & $\begin{array}{l}{[6,25,31-} \\
35]\end{array}$ \\
\hline & & Rofecoxib & & {$[20]$} \\
\hline & & SC-236 & $\downarrow \| L-1 \beta$-induced hyperalgesia & {$[10,21]$} \\
\hline & & SC-58125 & $\downarrow$ firing magnitude of C-nociceptors & {$[10,14,29]$} \\
\hline \multirow{6}{*}{$\begin{array}{l}\text { Nonselective } \\
\text { COX inhibitors }\end{array}$} & \multirow{6}{*}{$\begin{array}{l}\text { COX-1 and } \\
\text { COX-2 }\end{array}$} & Diclofenac & $\downarrow$ substance $\mathrm{P}$ & {$[26]$} \\
\hline & & Ibuprofen & $\downarrow T T X-R$ expression, $\downarrow P 2 X 3$ expression & $\begin{array}{l}{[10,26,28,} \\
32,36]\end{array}$ \\
\hline & & Indomethacin & $\begin{array}{l}\downarrow \text { BK-mediated CGRP release, } \downarrow \text { firing magnitude of C-nociceptors, } \downarrow \| L-1 \beta \text {-induced hyper- } \\
\text { algesia, } \downarrow \text { TNFa-sensitized neuronal response to capsaicin, } \downarrow \text { VEGF-induced growth cone } \\
\text { formation }\end{array}$ & $\begin{array}{l}{[14,21,25} \\
29,37-42]\end{array}$ \\
\hline & & Ketorolac & & {$[36]$} \\
\hline & & Paracetamol & $\downarrow P K C \varepsilon$ translocation & {$[26]$} \\
\hline & & Piroxicam & & {$[43]$} \\
\hline
\end{tabular}

baseline and inflammatory releases of $\mathrm{PGE}_{2}$ from DRG neurons were reduced after treatment with several COX inhibitors (nimesulide, celecoxib, diclofenac, ibuprofen, and paracetamol) [26].

Interestingly, resveratrol, a natural polyphenol $(2 \mathrm{mg} /$ $\mathrm{kg}$ ), exhibited an anti-nociceptive effect in carrageenanevoked hyperalgesia in rats when administered intraperitoneally, presumably by suppressing COX-2 expression in the DRG and spinal cord [19].

\section{Studies using localized pharmacological treatments}

The effect of local administrations has been examined using the partial sciatic nerve ligation (pSNL) model in rats [29]. In addition to indomethacin, the COX-2 inhibitors meloxicam and SC-58125 showed analgesic efficacy when subcutaneously injected into injured hind paws. The analgesia was restricted to the injected paws, implying that the mechanism may probably involve altered nociceptor function. Again in rats aged 18 months after pSNL, sciatic nerve perineural injection of NS-398 (a COX-2 inhibitor) also relieved chronic neuropathic pain [45]. In another study, the direct injection of a COX inhibitor (indomethacin, valeryl salicylate, or SC-236) into the L5-dominated peripheral field has commonly been shown to alleviate IL-1 $\beta$-induced hyperalgesia in the hind paws of rats [21].

\section{Studies using localized stimulation}

Subcutaneous injection of the isoprostanes 8-iso $\mathrm{PGE}_{2}$ and 8-iso $\mathrm{PGF}_{2 \alpha}$ has been shown to acutely lower the von Frey mechanical threshold, presumably through nociceptor sensitization. Those allodynic responses were at least partly rescued by ketorolac ( 1 and $10 \mathrm{mg} / \mathrm{kg}$ ) and ibuprofen treatments $(30 \mathrm{mg} / \mathrm{kg})$ and thus those authors suggested that not only isoprostane-specific receptor molecule-mediated sensitization, but local prostaglandin production were also responsible for the acute sensitization [36]. Overall, consistent with the results from transgenic studies of COXs, the results from studies of their pharmacological inhibition including cases specifically targeting the peripheral somatosensory system indicate that they contribute to pathological nociception.

\section{$\mathrm{PGE}_{2}$ and $\mathrm{PGD}_{2}$}

Which PGs most actively contribute to ascending pain signals is another question. As shown in Fig. $1, \mathrm{PGH}_{2}$ is subsequently metabolized into $\mathrm{PGE}_{2}, \mathrm{PGD}_{2}, \mathrm{PGI}_{2}$, or $\mathrm{TXA}_{2}$ by means of specific synthases. Accordingly, we here overviewed the actions of those four substances and then those of further metabolized PGs. Because $\mathrm{PGD}_{2}$ has often been comparably studied alongside $\mathrm{PGE}_{2}$, we present information about both of them here.

$\mathrm{PGE}_{2}$ is synthesized by the conversion of $\mathrm{PGH}_{2}$ through the action of one of three $\mathrm{PGE}_{2}$ synthases 
(PGESs), cytosolic PGES, membrane-bound microsomal PGES-1 (mPGES-1), and mPGES-2. Among the PGESs, one study showed that mPGES-1 was mainly coupled to COX-2-mediated $\mathrm{PGE}_{2}$ biosynthesis [46]. PGD synthase catalyzes another type of isomerization of $\mathrm{PGH}_{2}$ and two subtypes of PGD synthases have been identified [47]. The lipocalin-type PGD synthase (L-PGDS, also known as prostaglandin-H2 D-isomerase (PTGDS\} or glutathioneindependent prostaglandin $\mathrm{D}$ synthase) is an $\mathrm{N}$ glycosylated enzyme that does not necessarily require free sulfhydryl cofactors such as glutathione (GSH) to execute its catalytic function and has been principally detected in the brain, testis, and heart $[47,48]$. The other subtype of PGD synthase is hematopoietic PGD synthase (H-PGDS), which is a cytosolic GSH-dependent enzyme and is associated with the activity of GSH S-transferase. H-PGDS is expressed in immune cells, including mast cells and dendritic cells $[47,48]$. According to the studies below, PG generation by mPGES-1 and L-PGDS in sensory neurons appears to contribute to inflammatory pain development.

\section{Formation of $\mathrm{PGE}_{2}$ and $\mathrm{PGD}_{2}$ in the DRG and spinal cord $P G$ production from infiltrated immune cells}

When tissues are injured, prostaglandins produced by invading neutrophil and macrophage promote neuronal pain signals (see review: [49-51]). A recent work with transgenic mice whose the upstream transcription processes for PG-producing enzymes were genetically modified confirmed such an immune cell contribution in inflammatory pain models [52]. Moreover, both the neuronal and non-neuronal components of the peripheral somatosensory system have been shown to produce PGs.

\section{PG production from neurons}

During the early stage of research, chicken DRG were frequently used to gather information about PGs in the somatosensory system. Vesin and colleagues identified the PGs present in DRG homogenates from one-week-old chickens using a radio-labeled technique [53]. Two major PGs that were converted from the supplied $\left[{ }^{14} \mathrm{C}\right]$ arachidonic acid were $\left[{ }^{14} \mathrm{C}\right] \mathrm{PGE}_{2}$ and $\left[{ }^{14} \mathrm{C}\right] \mathrm{PGD}_{2}$, which indicated the presence of the enzymatic mechanism described above [53]. According to the same study, $\mathrm{PGD}_{2}$ was preferentially produced in primary somatosensory neurons, whereas $\mathrm{PGE}_{2}$ was mainly generated in fibroblastenriched locations (i.e., meninges and DRG capsules) [54]. The location of PGD synthase in the DRG population was then investigated using immunohistochemistry $[55,56]$. The immunoreactivity of L-PGDS was detected in $40 \%$ of small-diameter neurons, but in only $2 \%$ of large-diameter neurons, in DRG from 12-day-old chickens $[55,56]$. The immunoreactivity of H-PGDS was detected in the satellite cells and Schwann cells that surround chick DRG neurons [55]. Therefore, the two isozymes of PGD synthase are involved in $\mathrm{PGD}_{2}$ formation in $\mathrm{DRG}$ and, in particular, GSH-independent L-PGDS is selectively expressed in the nociceptor subpopulation.

Soon after these initial findings from chicken nerves were reported, investigations using rodents began. In cultured embryonic rat sensory neurons, TNFo-induced capsaicin hypersensitivity decreased under indomethacin treatment, indicating that the cultured neurons could intrinsically produce prostaglandins [37]. Radioimmunoassays defined the presence of $\mathrm{PGE}_{2}$ and $\mathrm{PGD}_{2}$ in the lumbar spinal cords of rats [14]. RT-PCR and in situ hybridization assays conducted by Schuligoi et al. confirmed the expression of mPGES-1 and LPGDS in the rat DRG and spinal cords, both of which were up-regulated after four hours of exposure to the endotoxin LPS [57]. An in vitro superfusion chamber study from the same group demonstrated that increases in $\mathrm{PGE}_{2}$ and $\mathrm{PGD}_{2}$ secretions could be observed in spinal cord slices from mice with systemic exposure to endotoxin for $24 \mathrm{~h}$, and that those secretions were prevented by the addition of lumiracoxib (100 $\mathrm{nM}$ ), a selective COX-2 inhibitor [13]. Grill et al. further demonstrated that the inflammation-induced promotion of $\mathrm{PGD}_{2}$ production depended on the action of COX-2, but not COX1 [18]. In the spinal cords of those inflamed mice, the expression of mPGES-1 and L-PGDS was up-regulated probably by non-neuronal components $[13,18]$. Those results indicate that the production of both $\mathrm{PGE}_{2}$ and $\mathrm{PGD}_{2}$ can be augmented via up-regulation of essential biosynthetic enzymes, such as the COXs, mPGES-1, and L-PGDS, in the DRG and spinal cord during inflammation. The expression of mPGES-1 in DRG neurons was later confirmed by immunohistochemistry [58], and that of L-PDGS has been confirmed in microarray and Western blot analyses [59].

Increased $\mathrm{PGE}_{2}$ levels were detected in injured peripheral nerves and their ipsilateral lumbar DRG 10 days after sciatic nerve injury, and they were suppressed by treatment with the non-selective COX inhibitor ibuprofen $(40 \mathrm{mg} / \mathrm{kg})$ [60]. Unlike the observations from chicken DRG, where $\mathrm{PGE}_{2}$ was hardly found in the neuronal components, the proinflammatory cytokine IL- $1 \beta$ facilitated $\mathrm{PGE}_{2}$ production in cultured rat DRG neurons through the extracellular signalregulated kinase (ERK)/p38 mitogen-activated protein kinase (MAPK) pathway, presumably via elevated COX-2 expression [20]. In the aged rats with pSNL neuropathy mentioned above [45], chronic neuropathic pain was associated with heightened $\mathrm{PGE}_{2}$ levels in the injured nerve, caused by persistent COX-2 expression [45].

$\mathrm{PGE}_{2}$ was also found to be produced and secreted from the satellite glial cells surrounding the DRG neurons in response to fractalkine (also known as chemokine $\{\mathrm{C}-\mathrm{X} 3-\mathrm{C}$ motif\} ligand 1 or CX3CL1), a chemokine released from DRG neurons when they are in an inflamed state [61]. Such evidence of the presence of $\mathrm{PGE}_{2}$ and $\mathrm{PGD}_{2}$ in the neuronal and glial components of the peripheral nociceptive pathway indicates that these PGs 
could considerably alter cellular functions. Receptor activation by secreted PGs may trigger those alterations.

\section{PG production from non-neuronal cells}

The data from a recent single-cell RNA sequencing study showed significant expression of the genes encoding PGproducing enzymes in not only neuronal, but also various non-neuronal components of a rodent brain, implying that secreted non-neuronal PGs might actively regulate neuronal functions [62]. In fact, multiple studies have confirmed that various non-neuronal cell types join in with PG formation in the peripheral somatosensory system (see review: [63]). For example, spinal astrocytes and microglia [64-66], Schwann cells of the sciatic nerve [67], and satellite glial cells surrounding trigeminal neurons [68] have been shown to produce $\mathrm{PGE}_{2}$ in the presence of tissue injury or inflammation. Taken together, PGs produced from neuronal, glial, and invaded immune cells locally play an important role in regulating the sensory neuronal function regarding pain signaling possibly in paracrine and autocrine manners.

\section{Genetic deletions of $\mathrm{PGE}_{2}$ and $\mathrm{PGD}_{2}$ synthases}

mPGES-1 and L-PGDS, known as greater contributors to nociceptive processing among the $\mathrm{PGE}_{2}$ and $\mathrm{PGD}_{2}$-producing enzymes, were genetically deleted and tested in several pain behavioral studies. Nociceptive writhing was commonly reduced in three acetic acid-induced writhing models using mPGES-1-deficient mice [69-71]. Kamei and colleagues further observed reduced writhing responses in an LPS-primed condition [70]. The reduction in acetic acid-induced writhing responses seen in Ptges (which encodes mPGES-1 protein)null mice was comparable to the effect seen with piroxicam when wild-type mice were treated [69]. Trebino et al. demonstrated that knockout mice displayed no significant difference in withdrawal latencies in hot plate assays compared with wild-types in the same study. In a different study, Ptgesnull mice exhibited decreased neuropathic pain, such as mechanical allodynia and thermal hyperalgesia, under L5 nerve transaction [72]. This result is interesting because reducing the $\mathrm{PGE}_{2}$ level is currently not considered to be a best analgesic strategy for relieving neuropathic pain. Controversial results have also been produced in other pain behavioral models. Ptges knockout mice failed to show a difference in zymosan-evoked mechanical hyperalgesia and formalin-induced phase 1 and 2 nociceptive responses [71]. The shunting of the substrate to other PG synthases possibly explains that unexpected result because some other PGs also play pro-nociceptive roles, as explained below [73]. An interesting result was produced in one Ptgds (which encodes LPGDS protein) knockout study in which intrathecally injected $\mathrm{PGE}_{2}$ caused heat hyperalgesia, but not mechanical allodynia, in Ptgds-deficient mice, suggesting that $\mathrm{PGD}_{2}$ generation at least partly contributes to the pro-nociceptive action of $\mathrm{PGE}_{2}$ [74].

\section{$\mathrm{PGE}_{2}$-activated EPs ( $\mathrm{PGE}_{2}$ receptors)}

$E P$ expressions in the peripheral somatosensory system

Secreted $\mathrm{PGE}_{2}$ interacts with its cognate G-protein coupled receptors, namely EP receptors located on the plasma membranes of neurons. The EP family is composed of four subtypes (EP1-EP4), each of which activates distinctive signaling pathways (reviewed in [75]). As shown in Fig. 2a, the EP1 receptor is associated with the Goq G protein, and EP1 activation triggers the cytosolic release of $\mathrm{Ca}^{2+}$ from the endoplasmic reticulum through phospholipase C (PLC)-mediated inositol 1,4,5trisphosphate (IP3) production [4, 76]. EP2 and EP4 receptors are coupled with Gos which amplifies cAMP production by activating adenylyl cyclase. Reversely, EP3 receptor-coupled Goi activation lowers the cAMP level by inhibiting adenylyl cyclase $[4,76]$. In mouse DRG, in situ hybridization tracking EP expression offered the first evidence of mRNA transcripts of Ptger1, Ptger3, and Ptger4 among the EP-encoding genes [77]. Later, Ptger1, Ptger2, Ptger3C, which is a Ptger3 splicing variant, and Ptger4 were detected in an RT-PCR analysis of rat DRG neurons [78]. More recently, Ptger $3 A, B$, and $C$ expressions were further confirmed in rat DRG [79]. In trigeminal neurons, EP2 and EP3 have been shown to be abundant in nociceptors [80]. The expression of EP2 in rat DRG was confirmed by a separate research group [81]. Although somatosensory EP expression itself has been shown repeatedly, its alteration in a pathological state remains unclear. Immunoreactivity to EP1 was temporarily increased and then returned to a normal level when the human brachial plexus nerve was injured [82]. In a rat model of cervical facet joint injury, which readily causes mechanical allodynia, EP2 expression in DRG neurons was elevated [81]. On the other hand, in vitro treatments of mouse DRG neurons with the pro-inflammatory cytokines, TNF $\alpha$ and IL-1 $\beta$ enhanced $\mathrm{PGE}_{2}$ production through the elevation of COX-2 expression, but there was no significant alteration in the mRNA levels of Ptger1Ptger4 [31]. A recent study showed that Ptger2 but not Ptger4 expression in DRG escalates in a murine model with endometriosis lesions [83].

\section{Pharmacological evidence for EP expression}

Pharmacological evidence of somatosensory EP expression has also been accumulating. A surgical incision in the middle of the L4-L6 spine lowered the mechanical threshold and was associated with heightened $\mathrm{PGE}_{2}$ levels in DRG neurons one to two weeks after surgery [84]. The sensitized mechanical response was reversed by oral administration of the EP1 antagonist, ONO-8713, for five days [84]. Direct injection of an EP1/EP2 (AH6809) or EP4 (AH2384810) antagonist into the L5 DRG significantly alleviated IL-1 1 -induced hyperalgesia in the hind paws of rats [21]. The EP3 agonist ONO-AE248 mimicked $\mathrm{PGE}_{2}$-induced attenuation of the activity of 


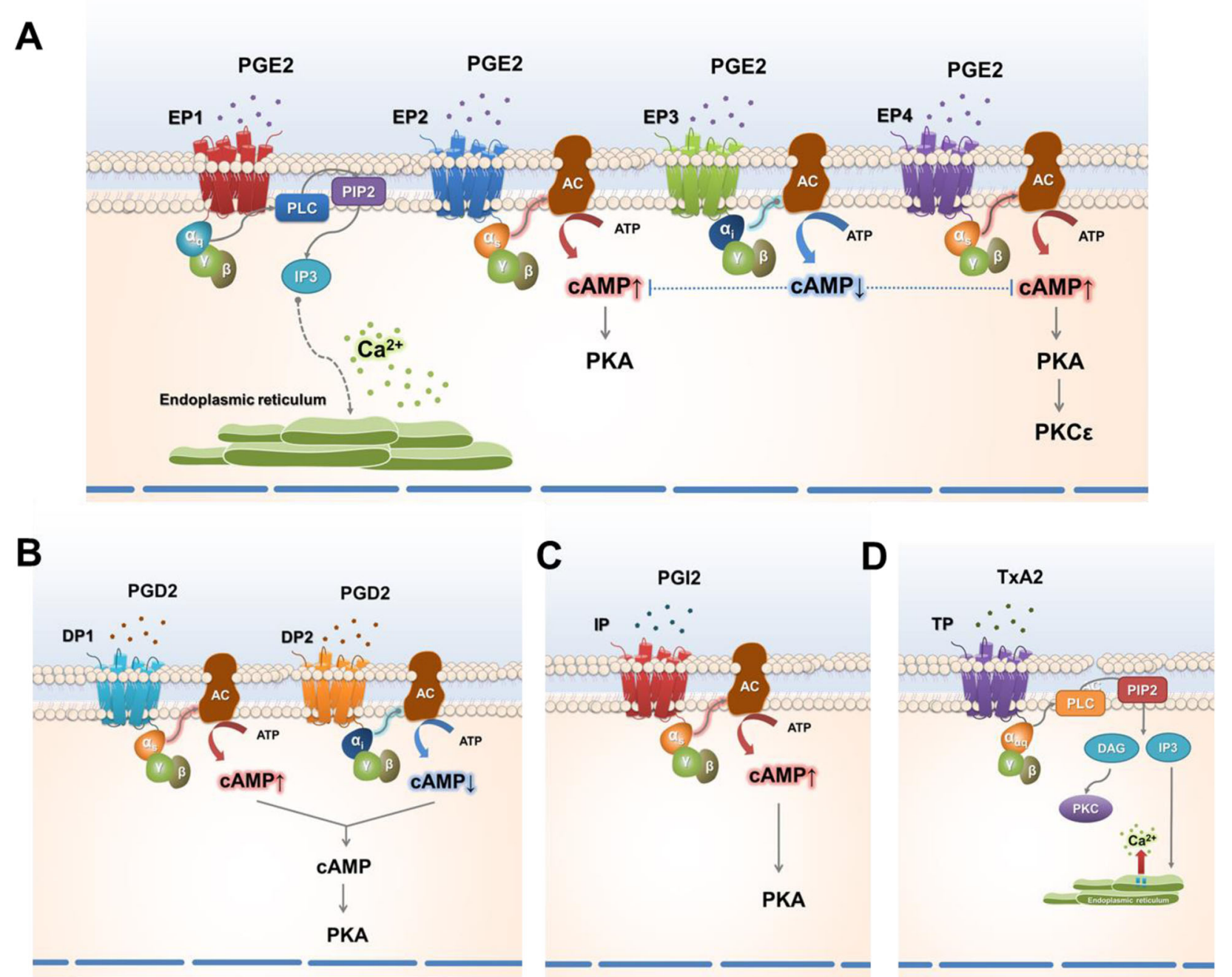

Fig. 2 Signaling pathways initiated by prostanoids released from peripheral inflammation. a $\mathrm{PGE}_{2}$-induced activation of EP receptors in somatosensory neurons. In somatosensory neurons, the EP1 receptor is associated with the G protein, Gaq and its activation triggers the release of intracellular $\mathrm{Ca}^{2+}$ from the endoplasmic reticulum through inositol 1,4,5-trisphosphate (IP3) production. EP2 and EP4 receptors are coupled with Gas, which stimulates cyclic adenosine monophosphate (CAMP) production by activating adenylyl cyclase (AC), whereas EP3 receptorcoupled Gai activation inhibits CAMP production by inhibiting AC. CAMP in turn activates protein kinase A (PKA), causing phosphorylation of various signaling proteins including epsilon type protein kinase C (PKC $)$. $\mathbf{b}$-d Signaling pathways initiated by the activation of DP, IP, and TP receptors in somatosensory neurons. The DP1-linked Gas stimulates intracellular CAMP production, whereas DP2-associated Gai inhibits CAMP production. The counter-action of DP1 and DP2 (b) receptors regulates CAMP accumulation in the cytosolic compartment. The activation of IP (c) or TP receptors (d) recruits Gas protein, activates $\mathrm{AC}$, and consequently raises the intracellular CAMP level

voltage-gated $\mathrm{Ca}^{2+}$ channels in acutely isolated mouse trigeminal neurons [85]. The same EP3 agonist suppressed the $\mathrm{PGE}_{2}$-facilitated activity of a tetrodotoxin (TTX)-resistant voltage-gated $\mathrm{Na}^{+}$channel (TTX-R) in cultured DRG neurons without altering the basal channel activity $[79,86]$. Interestingly, a recent study demonstrated that one outcome from EP3 actions on DRG neurons could be pro-nociceptive because sulprostone, an EP agonist with higher efficacy on EP1 and EP3 than EP3 and EP4, induced the secretion of CC motif-chemokine ligand 2 (CCL2) in DRG cultures from wild-type mice, whereas the effect was significantly milder in Ptger3 (which encodes EP3 protein)-deficient mice. The data indicates that EP3-induced CCL2 secretion from DRG neurons could promote pain by activating $\mathrm{C}-\mathrm{C}$ motif chemokine receptor 2 (CCR2), which is expressed in spinal neurons and microglia [87].

The presence of EPs in the spinal cord has been implied mostly by pharmacological evidence. The spinal application of an EP1 (ONO-DI-004), EP2 (butaprost), or EP4 (ONO-AE1-329) agonist caused dorsal horn hyperexcitability in an in vivo electrophysiology test when the relevant knee joint and ankle were mechanically stimulated under normal conditions [86]. For an inflamed knee joint, only spinal application of the EP1 
agonist (ONO-DI-004) further facilitated the hyperexcitability of the spinal dorsal horn neurons, whereas the application of the EP3 (ONO-AE-248) and EP4 agonists (ONO-AE1-329) did not [79, 86]. The same application of the EP3 agonist (ONO-AE-248) reversed the hyperexcitability caused by knee joint inflammation, which could be underpinned by Goi-coupled signaling [86]. Similarly, intrathecal administration of an EP1 antagonist (ONO8711) in rats blunted $\mathrm{PGE}_{2}$-induced mechanical hyperalgesia in a dose- and time-dependent manner [88]. It is intriguing that this study demonstrated Ptger1 expression only in the DRG and failed to show it in the spinal cord, using in situ hybridization, suggesting that EP1 might facilitate presynaptic signals in the central termini of DRG neurons. An intracellular calcium imaging analysis of spinal cord slices from the same study showed that ONO8711 largely inhibited the $\mathrm{PGE}_{2}$-induced $\mathrm{Ca}^{2+}$ influx in laminae II-VI in the dorsal horn, which could result from decreased presynaptic functions [88]. Collectively, these data demonstrate that EPs are expressed in peripheral somatosensory components, and EP1, EP2, and EP4 in particular appear to play primarily pro-nociceptive roles.

\section{Kinase-mediated EP signal transduction}

Studies investigating the functional roles of EPs have also expanded knowledge of the downstream information regarding the actions of protein kinases. Many types of DRG neuronal ion channels that confer electrical excitability experience phosphorylation of their intracellular amino acids, which frequently leads to enhanced channel activity. EP-induced signaling mediates phosphorylation by PKA and PKC (Fig. 2). Detailed mechanisms are mentioned below for the facilitated activities of TTX-R, voltage-gated $\mathrm{Ca}^{2+}$ channels, purinoceptors, and TRP channels. Interestingly, there appears to be modulation between PKA and PKC actions in EP signaling. Gold and colleagues suggested that PKC activity appears to be necessary for PKAmediated positive modulation of TTX-R activity [89]. A differential result has also been reported. In the L4-L5 DRG, an in vivo intraplantar injection of $\mathrm{PGE}_{2}$ (100 ng per paw) robustly elevated not only PKA activity 30 min later, but also $\mathrm{PKC} \varepsilon$ activity three hours after injection [90]. This in vivo study further showed that the effect on PKCE disappeared when PKA was pharmacologically inhibited, suggesting that PKA is able to regulate PKC $\varepsilon$ activity [90].

Janus kinase 2 (JAK2) is a cytoplasmic tyrosine kinase that is activated through pro-inflammatory cytokine signaling [91]. A JAK2-induced transcriptional cascade has been shown to be involved in inflammatory and neuropathic pain [92, 93]. Interestingly, a recent report has demonstrated that $\mathrm{PKC} \varepsilon$ is a merger point for the actions of $\mathrm{PGE}_{2}$ and JAK2 [94]. Intrathecal injection of the JAK2-selective inhibitor AG490 blocked the membrane translocation of PKCE in the L5 DRG in a carrageenan- inflamed hind paw model [94]. The same administration also blunted the hyperalgesia induced by an intraplantar injection of $\mathrm{PGE}_{2}$ or carrageenan [94]. Furthermore, they showed that an in vitro pre-incubation of DRG neurons with AG490 prevented the potentiation of a TRPV1mediated $\mathrm{Ca}^{2+}$ influx by $\mathrm{PGE}_{2}$. Although the transcriptional link associated with JAK2-induced PKCe translocation remains elusive, that study again emphasizes the importance of $\mathrm{PKC} \varepsilon$ as a signal transducer for the pro-nociceptive actions of $\mathrm{PGE}_{2}$ and suggests that JAK2 could intervene in that process.

Nitric oxide (NO) has been suggested as a way to mediate PKA signaling. The intradermal injection of $\mathrm{PGE}_{2}$ in the paws of rats caused mechanical hyperalgesia, which was inhibited by the NO synthase (NOS) inhibitor $\mathrm{N}^{\mathrm{G}}$-monomethyl-L-arginine (L-NMMA) [95]. L-NMMA also inhibited mechanical hyperalgesia induced by the stimulation of $\mathrm{PGE}_{2}$ downstream steps such as injections of 8-bromo-cAMP (a stable membrane-permeable analog of cAMP) or forskolin (an adenylyl cyclase activator). However, it failed to alter hyperalgesia produced by the injection of the PKA catalytic subunit, indicating that $\mathrm{NO}$ could play a role in the interaction between adenylyl cyclase and PKA [95].

EP4 also appears to regulate cytokine expression. Normally, interleukin-6 (IL-6) is detected in a very small fraction of C-nociceptor neurons. pSNL neuropathy causes expanded IL-6 expression in a wider subset of DRG populations, which has been shown to be mediated through EP4 activation [96]. The incubation of cultured DRG neurons with $\mathrm{PGE}_{2}$ resulted in elevated IL- 6 expression, which depended on EP4 activation and kinase activation [96]. Tse and collogues revealed an interactive event between the activation of EP4 and toll-like receptor 4 (TLR4) in their series of studies although much remains be explored regarding the kinase action: LPS-induced TLR4 activation regulated the production of $\mathrm{PGE}_{2}$ in the sensory neurons and glial cells of rat DRG [97, 98]. Also, DRG neuron-derived $\mathrm{PGE}_{2}$ modulated TLR4 activity dependent on the activation of EP4 in DRG neurons and glial cells in an autocrine and paracrine manner [99].

\section{Differential pro-nociceptive roles of EP2 and EP4}

The role of EP2 in $\mathrm{PGE}_{2}$-induced pro-nociception has mainly been studied in the spinal cord. Treatment with the EP2 agonist butaprost induced an inward current in the deep dorsal horn neurons of rats in a way similar to that seen with $\mathrm{PGE}_{2}$ exposure [100]. The Zeilhofer group reported a different aspect of EP2 activation that led to a Gsdependent reduction in the glycinergic inhibitory transmission in rat superficial dorsal horn neurons [101]. Two years later, a study using zymosan and CFA-induced mouse inflammation models confirmed that such EP2-mediated interruption of the spinal glycinergic transmission contributed to inflammatory pain [102]. This spinal EP2-induced 
pro-nociceptive paradigm was again confirmed with Ptger2 (which encodes EP2 protein) knockouts in the inflammatory pain model [103], but not in the formalin-induced pain model or a neuropathic pain model [104]. Two recent studies reported interesting findings: spike timing-dependent long-term potentiation occurred in the lamina I spinal projection neurons of female mice in an EP2-dependent manner in a study using the EP2 selective antagonist PF 04418948 and the agonist butaprost, which awaits the quantification of in vivo pain contribution in comparison to the above findings from the effects on the superficial inhibitory and deep excitatory circuits [105]. Elevated Ptger 2 expression in the DRG was recently shown in a murine endometriosis model. In the same study, EP2 antagonism, targeting receptors that probably include the ones expressed in DRG, was more effective in reducing both primary and secondary hyperalgesia than EP4 antagonism [83].

In DRG neurons, numerous studies focused first on $\mathrm{PGE}_{2-}$ mediated EP4 activation. It was determined that $\mathrm{PGE}_{2}$ and $\mathrm{PGE}_{1}$ (which is not derived from arachidonic acid but from dihomo- $\gamma$-linolenic acid) induced cAMP accumulation by stimulating adenylyl cyclase in rat DRG neurons [106, 107]. Only the EP4 agonist (ONO-AE1-329) caused intracellular cAMP accumulation in adult rat DRG neurons, while EP1 (ONO-DI-004), EP2 (ONO-AE1-259-01), and EP3 (ONOAE1-329) agonists did not [108]. Interestingly, only EP4 expression, not EP1-3 expression, was elevated in L5 DRG neurons following CFA-induced unilateral hind paw inflammation in a different study [109]. Lin et al. also demonstrated that silencing EP4 action with an intrathecally administered EP4 antagonist (AH23848) or with its knockdown using short hairpin RNA (shRNA) rescued thermal and mechanical hypersensitivity without changing basal pain behavioral sensitivity in this rodent peripheral inflammation model [109]. AH23848 also suppressed $\mathrm{PGE}_{2}$-induced sensitization of the nociceptive ion channel TRPV1 to its agonist capsaicin in DRG neurons [109]. St-Jacques and Ma have shown that $\mathrm{PGE}_{2}$-mediated EP4 activation led to increased translocation of the EP4 protein to the plasma membrane of DRG neurons. They also demonstrated that EP4 recycling in DRG neurons is facilitated during inflammation, which enhances $\mathrm{PGE}_{2}$ sensitivity $[110,111]$. Another study by that group showed $\mathrm{PGE}_{2}$ can facilitate anterograde axonal trafficking of the EP4 protein, resulting in increased EP4 availability at the axonal terminal of nociceptor neurons [112]. The expression of EP4 was also found in glial cells isolated from the DRG, and its functionality was confirmed by detecting specific agonist-induced cAMP production that was preventable by antagonist application [113].

\section{$P G D_{2}$-activated DPs ( $\mathrm{PGD}_{2}$ receptors)}

The presence of DP receptors in sensory neurons was first predicted by pharmacological studies that showed mild cAMP accumulation in DRG neurons after $\mathrm{PGD}_{2}$ exposure [106, 107]. $\mathrm{PGD}_{2}$-evoked CGRP release from trigeminal neurons was prevented by pre-incubation with the DP1 antagonist BWA868C [114]. PGD $_{2}$ binds to and activates DP receptors, which have two subtypes: DP1 and DP2 (Fig. 2b). The DP1-linked Gos stimulates adenylyl cyclase activity in the same manner as the EP2 and EP4 receptors, whereas DP2-associated Goi inhibits the same enzyme as the EP3 receptor (Fig. 2). Therefore, cAMP accumulation and CGRP secretion implies that DP1 action is predominant in sensory neurons. A decade after that research, DP1 and DP2 proteins were shown to be broadly detected in small to large-sized neurons of the lumbar DRG [115]. Ebersberger and colleagues also pharmacologically confirmed that a selective DP1specific agonist (BW245C) augmented the excitability of DRG neurons by facilitating both the conductance and voltage-dependence of TTX-R, which is presumably encoded by the Nav1.8 or Nav1.9 genes. On the other hand, treatment with the DP2 agonist $15(\mathrm{R})-\mathrm{PGD}_{2}$ occasioned no response. Interestingly, the DP2 agonist interfered with the $\mathrm{Na}^{+}$conductance mediated by DP1 activation, suggesting that DP2 functions as a negative regulator of DP1 activation [115]. Because the net effect of $\mathrm{PGD}_{2}$ treatment is the enhancement of the $\mathrm{Na}^{+}$ current, $\mathrm{PGD}_{2}$ appears to be pro-nociceptive, and DP1 may predominantly mediate that effect in these afferent nociceptors. A quantitative real-time RT-PCR analysis confirmed the predominance of Ptgdr1 (encoding DP1) expression over Ptgdr2 expression in both DRG and trigeminal neurons [116]. Nociceptor-specific Ptgdr1 expression has been replicated using different methods, such as a transcriptomic analysis using DRG neurons and an in situ hybridization assay using trigeminal neurons $[117,118]$. Unlike the data for DP receptors in DRG, results concerning spinal DPs have been relatively confusing. Ptgdr1 and Ptgdr2 expression was detected in murine spinal dorsal horn neurons [18]. Interestingly, the mRNA levels of both Ptgdr1 and Ptgdr2 increased under systemic inflammation induced by the intraperitoneal injection of an endotoxin $(1 \mathrm{mg} / \mathrm{kg})$, but their protein levels did not [18]. Telleria-Diaz et al. conducted in vivo spinal recordings and showed that DP1 activation prevented electrical discharges, and DP1 inhibition promoted them when inflamed knee joints were mechanically stimulated [119]. It is possible that spinal interneuron subsets serve differential roles using the DP1 receptor.

\section{Pro-nociceptive effectors of $\mathrm{PGE}_{2}$ signaling}

As mentioned above, EP1-2, EP4, and DP1-mediated signaling is predominant in directing the action of $\mathrm{PGE}_{2}$ and $\mathrm{D}_{2}$ to pro-nociceptive outcomes in the peripheral somatosensory system. Those outcomes are finally achieved by increasing the excitability and secretability of nociceptors. The molecular effectors of this increased excitability and secretability have 
been studied mainly with regard to the actions of $\mathrm{PGE}_{2}$ and are categorized below (Fig. 3).

\section{The inhibition of slow spike after-hyperpolarization (AHP slow $_{\text {) }}$ by $P G E_{2}$}

In 1976, Coleridge and colleagues first reported the promotive effects of $\mathrm{PGE}_{2}$ on C-fiber impulses in the lungs of anesthetized dogs [120]. Since then, many studies have investigated the effects of prostaglandins on visceral afferent neurons. The application of $\mathrm{PGE}_{1}, \mathrm{PGE}_{2}$, and $\mathrm{PGD}_{2}$ (but not $\mathrm{PGF}_{2 \alpha}$ ) attenuated $\mathrm{Ca}^{2+}$-dependent AHPSlow, leading to increases in the excitability of the Cfibers in the leporine nodose ganglion [121, 122]. The inhibitory action of PGs on $\mathrm{AHP}_{\text {Slow }}$, which is known to use the intracellular $\mathrm{Ca}^{2+}$-activated $\mathrm{K}^{+}$channel $\left(\mathrm{K}_{\mathrm{Ca}}\right)$, appeared to be independent of their effect on extracellular $\mathrm{Ca}^{2+}$ influx, suggesting that other mechanisms, such as an intracellular signaling, may be important [123]. As a final outcome, the inhibition of $\mathrm{AHP}_{\text {Slow }}$ by $\mathrm{PGE}_{2}$ and $\mathrm{PGD}_{2}$ caused membrane excitability to increase due to augmented membrane resistance and depolarization to an extent [122]. That contribution of $\mathrm{AHP}_{\text {Slow }}$ was partly replicated in cultured rat DRG neurons [124]. Essentially, only a subpopulation of nociceptors exhibited $\mathrm{AHP}_{\text {Slow. }}$. $\mathrm{PGE}_{2}$ suppressed $\mathrm{AHP}_{\text {Slow }}$ in those nociceptors, which increased the frequency of action potentials [124]. It remains elusive which subtypes of $\mathrm{K}_{\mathrm{Ca}}$ channels are inhibited by $\mathrm{PGE}_{2}$ action. Although $\mathrm{AHP}_{\text {Slow }}$ is known to be uninvolved in setting the threshold for action potential generation, $\mathrm{PGE}_{2}$ exposure also reduced that threshold [124]. Therefore, those authors suggested that $\mathrm{PGE}_{2}$ may also modulate other electro-excitatory molecules in addition to $\mathrm{AHP}_{\text {Slow, }}$ which is currently considered TTX-R [124].

\section{The augmentation of TTX-R Na+ currents by $P G E_{2}$}

Voltage-gated $\mathrm{Na}^{+}$channels (VGSCs) play an essential part in the initiation and propagation of action potentials in neurons. Sensitivity to TTX in its blockade of VGSCs has long been a pharmacological standard for subcategorizing VGSCs. In small-diameter DRG nociceptors,

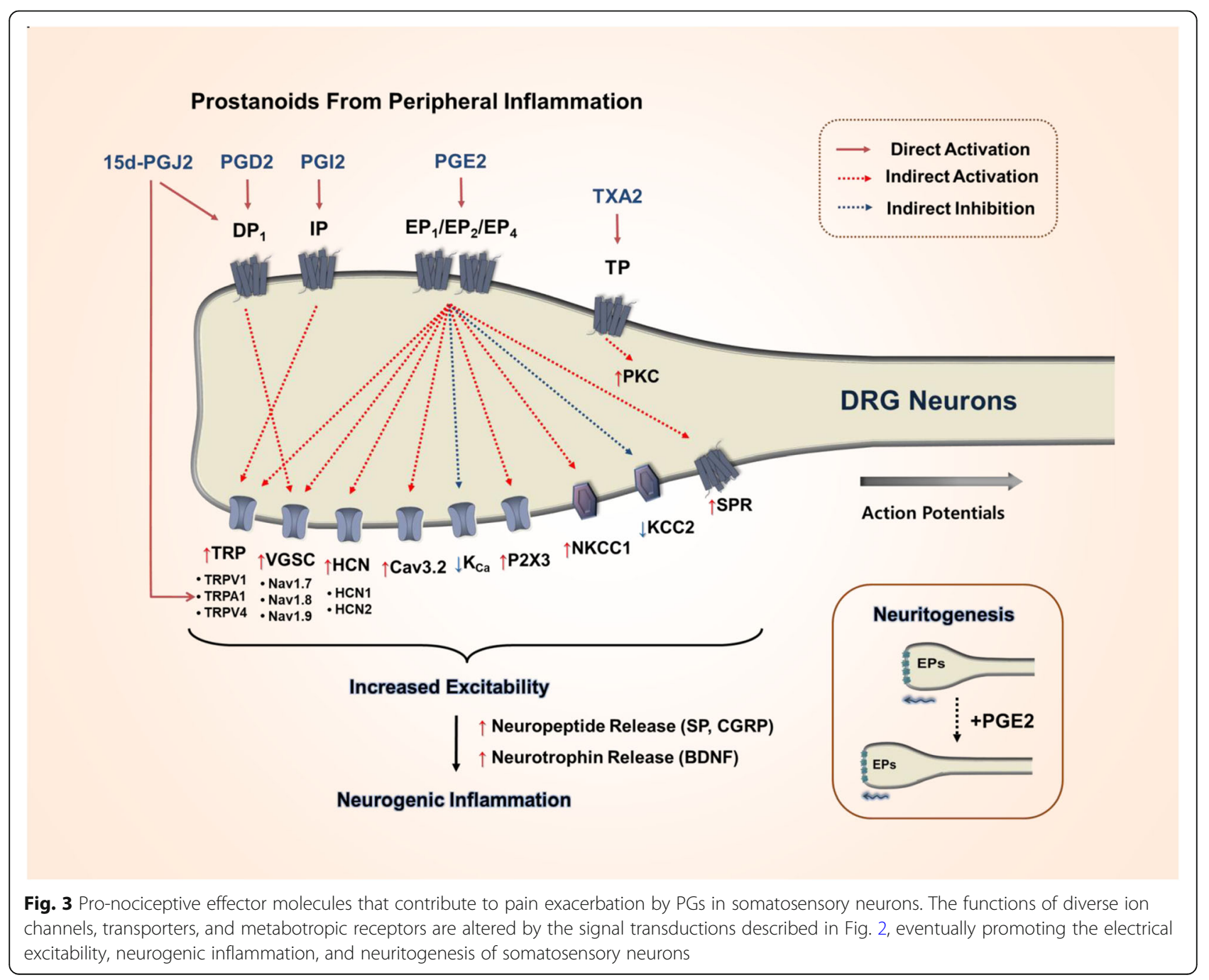


$\mathrm{PGE}_{2}$ has been shown to increase the magnitude of TTX- $\mathrm{R} \mathrm{Na}^{+}$currents (TTX-R $\mathrm{I}_{\mathrm{Na}}$ ) and causes a hyperpolarizing shift in its steady-state inactivation curve, which was shown to depend on the cAMP-PKA pathway [125]. The cAMP-dependent phosphorylation of Nav1.8, most prevalently responsible for TTX-R $\mathrm{I}_{\mathrm{Na}}$, caused hyperexcitability in membrane potential recordings of COS-7 cells heterologously overexpressing Nav1.8 [126]. Gold and colleagues found that not only PKA but also PKC contribute to the positive modulation of TTX-R activity in rat DRG neurons [89]. Interestingly, they suggested that PKC activity might be required for PKA-mediated modulation of TTX-R $\mathrm{I}_{\mathrm{Na}}$ [89]. $\mathrm{PGE}_{2}$ application has also been shown to promote TTX- $\mathrm{R} \mathrm{I}_{\mathrm{Na}}$ in endogenous Nav1.8 and Nav.1.9 channels in small-diameter DRG neurons [127, 128]. Moreover, Rush and colleagues have shown that $\mathrm{PGE}_{2}$ enhances Nav1.9-specific $\mathrm{Na}^{+}$currents in Nav1.8-deficient DRG neurons [129]. Jang and colleagues recently showed that $\mathrm{PGE}_{2}$ potentiates $\mathrm{GABA}_{\mathrm{A}}$-mediated $\mathrm{Ca}^{2+}$ transients and membrane depolarization in nociceptive DRG neurons via EP4 activation [38]. This potentiation does not seem to be caused by directly altering $\mathrm{GABA}_{\mathrm{A}}$ activity or intracellular $\mathrm{Cl}^{-}$homeostasis, but by increasing Nav1.8 activity [38]. TTX-S in A $\delta$ nociceptors also appears to be sensitized in an adenylyl cyclase-PKA dependent fashion, which awaits replication [130, 131].

In vivo models have also corroborated the effect of $\mathrm{PGE}_{2}$ on TTX-R $\mathrm{I}_{\mathrm{Na}}$. The intrathecal injection of an antisense ODN for Nav1.8, resulting in its knockdown, attenuated $\mathrm{PGE}_{2}$-induced hyperalgesia in rats [132]. The same study confirmed that in vitro treatment of cultured DRG neurons with an ODN for Nav1.8 selectively lowered TTX-R $\mathrm{I}_{\mathrm{Na}}$ density compared with untreated neurons [132]. Longitudinal incisions on rat hind paws caused a decrease in mechanical withdrawal thresholds and an increase in TTX-R $\mathrm{I}_{\mathrm{Na}}$ in DRG neurons [27]. One day and two days after the incision was made, the concentrations of $\mathrm{PGE}_{2}$ and CGRP were both significantly elevated in the paw tissue and DRG neurons. When the rats were orally treated with celecoxib (30 $\mathrm{mg} / \mathrm{kg}$ ) one hour before and $12 \mathrm{~h}$ after incisional surgery, mechanical pain behaviors, TTX-R $\mathrm{I}_{\mathrm{Na}}$, and the concentrations of $\mathrm{PGE}_{2}$ and CGRP were commonly downregulated [27]. Another in vivo model proposed a new molecular mechanism for this augmentation of TTX-R currents. The subcutaneous injection of CFA aggravated mechanical and thermal pain behaviors and also led to the increased expression of Nav1.7 and Nav1.8 in DRG neurons [32]. Those authors suggested that $\mathrm{PGE}_{2}$ contributes to this elevated expression of the TTX-Rs by showing that oral administration of COX inhibitors, either ibuprofen $(200 \mathrm{mg} / \mathrm{kg})$ or NS-393 $(10 \mathrm{mg} / \mathrm{kg})$, blunted both the elevation of TTX-R expression and the heightened pain behaviors [32]. Direct $\mathrm{PGE}_{2}$ exposure replicated the increased transcription and translation of Nav1.7 in an explant culture of trigeminal ganglia, which appeared to be mediated by EP2 activation [133]. Interestingly, increased protein translocation also seems to be involved. It has been demonstrated that $\mathrm{PGE}_{2}$-activated PKA directly phosphorylates the RRR motif of the first intracellular loop of the Nav1.8 channel protein, facilitating the membrane localization of Nav1.8 [134]. Deletion of the Nav1.8 gene, however, failed to generate firm evidence. $\mathrm{PGE}_{2}$-induced hypersensitivity and neuropathic pain behaviors in mice were unaltered by a Nav1.8-null mutation [135]. These results suggest that the compound actions of other effectors for neuronal excitability including those of multiple types of TTX-R may be required for the pro-nociceptive function of $\mathrm{PGE}_{2}$.

Despite the small number of studies conducted, $\mathrm{PGD}_{2}$ has also been shown to increase the conductance and maximal current amplitudes of TTX- $\mathrm{R} \mathrm{I}_{\mathrm{Na}}$ in rat adult DRG neurons by means of Nav1.8 or Nav1.9 activation [115]. The specific activation of Gos-coupled DP1 receptors appears to be required for this facilitation, which was neutralized by the activation of the Goi-coupled DP2 receptor [115]. Thus, $\mathrm{PGD}_{2}$ may regulate TTX-R $\mathrm{I}_{\mathrm{Na}}$ through a balance of DP1 and DP2 receptor activation.

\section{The effect of $\mathrm{PGE}_{2}$ on Cav3.2 voltage-gated $\mathrm{Ca}^{2+}$ channels}

Sekiguchi and colleagues have confirmed that the EP4cAMP- PKA axis is responsible for $\mathrm{PGE}_{2}$-induced mechanical hyperalgesia [136]. They suggested that one of the final molecular effectors for this pathological pain is the T-type voltage-gated $\mathrm{Ca}^{2+}$ channel (Cav3.2) of nociceptors [136]. Voltage-dependent responses of Cav3.2 were sensitized by PKA-catalyzed phosphorylation. Furthermore, A-kinase anchoring protein 150 (AKAP150), bound directly to Cav3.2, has been shown to facilitate the action of PKA [136].

\section{The effect of $P G E_{2}$ on purinergic $P 2 X$ purinoceptors}

Adenosine triphosphate (ATP) in the peripheral somatosensory system has been recognized as an important inflammatory mediator that evokes nociception [137]. Cation influx through the ionotropic ATP receptor P2X, when activated by binding to extracellularly secreted ATP, causes neuronal depolarization, which leads to the generation and exacerbation of pain signaling. Interestingly, this ATP-mediated hyperalgesia was potentiated by coinjection with $\mathrm{PGE}_{2}$ [138]. Later studies have explored the molecular mechanism of this pathway. Wang et al. showed that $\mathrm{PGE}_{2}$-mediated cAMP production contributes to P2X activation in DRG neurons [139]. Interestingly, the crucial receptor subtype associated with $\mathrm{PGE}_{2}$ action for P2X activation was found to be EP3, which is known to down-regulate cAMP in general [139]. Using their P2X3 potentiation model, Wang and colleagues also 
suggested that a mechanism for the signaling switch from PKA to PKC, which has been demonstrated in many other $\mathrm{PGE}_{2}$ studies, is mediated by the cAMP-responsive guanine nucleotide exchange factor 1 (Epac) protein [140]. Recently, the same group has further shown that Epacmediated PKC signaling facilitates the membrane expression of P2X3 by increasing F-actin levels in DRG neurons, contributing to $\mathrm{PGE}_{2}$-sensitized P2X3 currents [141]. Pharmacological evidence for P2X3 involvement has also been provided. P2X3 expression was augmented in rat DRG neurons in a chronic constriction injury (CCI) neuropathic pain model and returned to a normal level after treatment with ibuprofen and celecoxib [28]. $\mathrm{PGE}_{2^{-}}$ induced hyperalgesia was relieved by treatment with a P2X3 inhibitor (A317491) or by P2X3 knockdown using an antisense ODN [142]. In the same study, PKC $\varepsilon$ was determined to be the most critical isozyme of PKC in P2X3mediated hyperalgesia. Taken together, these findings indicate that $\mathrm{PGE}_{2}$ facilitates the action of $\mathrm{P} 2 \mathrm{X} 3$ via the sequential activation of PKA and PKC signaling, which produces sensitized responsiveness to ATP, an important inflammatory mediator.

\section{The effect of $P G E_{2}$ on the TRPV1 channel}

TRPV1 is considered to be the most important receptor-ion channel expressed in the A $\delta$ - and C-fibers of DRG. TRPV1 activation depolarizes the nociceptor population via cation influx in direct response to diverse harmful stimuli such as noxious heat, lipid peroxides, and leukotrienes and pungent chemicals such as capsaicin and tarantula toxin, generating and exacerbating pain [143-145]. In addition, TRPV1 activation in dorsal horn neurons is commonly suggested to contribute to pain transmission [146, 147]. Furthermore, many inflammatory mechanisms have been shown to augment TRPV1 activity, which explains an important aspect of inflammatory pain. For example, BK, histamine, TNF, and nerve growth factor (NGF) activate and/or sensitize TRPV1 via their specific signal transductions that use PLC, phospholipase A2 (PLA2), phosphoinositide 3-kinase (PI3K), and MAPK [148]. In this context, there have been important findings in PG research exploring whether and how PG signals and TRPV1 are linked, particularly regarding the actions of $\mathrm{PGE}_{2}$ and $\mathrm{PGI}_{2}$.

Even before TRPV1 was cloned, the Levine group had shown that $\mathrm{PGE}_{2}$, as well as $\mathrm{PGI}_{2}$, potentiates capsaicininduced currents in adult rat DRG neurons and also successfully replicated that potentiation effect using cAMP analogs [149]. Similar results were obtained in a study that better mimicked physiological $\mathrm{PGE}_{2}$ and cAMP concentrations and conducted single channel recordings [150]. Comprehensive investigations into TRPV1 signaling were completed after the TRPV1 gene and protein were identified. Using nociceptors cultured from wild-type animals and TRPV1 and EP transgenic knockouts, heterologous expression platforms transfected with either intact or phosphorylation-resistant TRPV1 clones, and specific pharmacological agents, the Tominaga group has thoroughly observed the signal transduction of TRPV1 [151]. As a result, they determined that the activation of EP1/ EP4 and IP (prostaglandin I2 receptor) was critical for TRPV1 sensitization by $\mathrm{PGE}_{2}$ and $\mathrm{PGI}_{2}$, respectively, and that the specific PGs do not show strong cross-reactivity for their receptor activation [151]. In the same study, TRPV1 phosphorylation by PKC $\varepsilon$ and PKA were both important downstream effects, but the time-scales for the peak effects differed: PKCe-mediated potentiation occurred first, around one minute after $\mathrm{PGE}_{2}$ exposure; several minutes later, PKA action began. They confirmed that Goq-coupled PKC $\varepsilon$ activation depends on preceding PLC activation whereas Gos-coupled PKA activation depends on cAMP production. This time-differential activation was more prominent in IP activation by $\mathrm{PGI}_{2}$, because nanomolar concentrations of $\mathrm{PGI}_{2}$ induced only the PKAdependent slow effect whereas higher concentrations produced both the slow effect and the PKC-mediated fast effect, confirming an earlier biochemical study that had used other tissues [152] (Namba et al., 1994). Such potentiation occurred not only in capsaicin responsiveness, but also in the heat responsiveness of TRPV1, which displayed a reduction in the temperature threshold of at least 10 degrees [151]. This appears to be a striking finding because the data indicate that prostaglandin-mediated inflammation can cause constant pain in response to normal body temperatures via TRPV1 potentiation.

More evidence for TRPV1 as an effector of prostaglandin signaling has been further reported. Two independent groups have demonstrated that AKAP150, which was also reported to be important for Cav3.2-mediated action, is essential for TRPV1 sensitization by $\mathrm{PGE}_{2}$ in DRG neurons and trigeminal neurons [153, 154]. AKAP150 was shown to physically bind to the TRPV1 protein. Once bound, PKA can anchor it in place, which could raise the efficiency of the PKA approach in targeting TRPV1 sequences for phosphorylation. Very recently, $\mathrm{PGE}_{2}$ has also been shown to elevate TRPV1 expression and further promote its translocation to the plasma membrane [155]. Therefore, $\mathrm{PGE}_{2}$ appears to facilitate the expression, trafficking, and activity of TRPV1, which promotes the nociceptive signaling of somatosensory neurons. Unlike the $\mathrm{PGE}_{2}$-TRPV1 relationship, few studies have examined the functional interaction between $\mathrm{PGD}_{2}$ and TRPV1 in the somatosensory system. The Hucho group recently emphasized the possible involvement of $\mathrm{PGD}_{2}$ by showing that the DP1 receptor is highly enriched in the TRPV1-positive subpopulation of nociceptors compared with other subsets [117]. Intriguingly, those authors also suggested that $\mathrm{PGD}_{2}$ secreted from large- 
diameter $A \beta$ fibers, which displayed higher expression of L-PDGS than nociceptors in their transcriptomic analysis, may act on the DP1 of TRPV1-positive nociceptors in a paracrine manner.

\section{The effects of $P G E_{2}$ on other TRP channels}

Other nociceptive TRP channels appear to experience similar sensitization upon $\mathrm{PGE}_{2}$ exposure. The activity of TRPV4, which is responsible for detecting noxiously mechanical stretches and hypoosmolality, was first shown to be augmented by $\mathrm{PGE}_{2}$ exposure in a series of studies conducted by the Levine group [156-160]. They used this facilitation paradigm to establish an in vivo TRPV4mediated pain behavioral model, in which rodents primed acutely by intraplantar injection of $\mathrm{PGE}_{2}$ exhibited hypoosmolality-induced flinches that were not readily observed in unprimed animals probably due to the presence of TRPV4 in a very small subset of nociceptors [161]. The Hwang group has further shown the utility of that model in screening TRPV4 modulators [162-165].

The contribution of the ankyrin subtype 1 of TRP (TRPA1) to $\mathrm{PGE}_{2}$-induced hyperalgesia has been reported. TRPA1 is a nonselective cation channel expressed in a subset of C-fibers and is comparable to TRPV1 in its extensive coverage of its sensible stimuli which are all painful. For example, TRPA1 is activated by noxiously cold temperatures $\left(<17^{\circ} \mathrm{C}\right)$, mechanical stretches, and endogenous and exogenous irritants (e.g. lipid peroxides, allyl isothiocyanate $\{$ AITC $\}$, cinnamaldehyde, and acrolein) $[166,167]$. Dall'Acqua et al. demonstrated that $\mathrm{PGE}_{2}$-mediated hyperalgesia is blunted by both pharmacological and genetic inhibition of TRPA1 [168]. Hyperalgesia induced by PKA and PKCE was also reduced by TRPA1 inhibition, suggesting that those enzymatic processes are involved in TRPA1's contribution to pain signaling [168].

\section{The regulation of cellular $\mathrm{cl}$ homeostasis by $\mathrm{PGE}_{2}$}

The intracellular $\mathrm{Cl}^{-}$level determines whether and to what extent the activation of $\mathrm{Cl}^{-}$channels such as $\mathrm{GABA}_{\mathrm{A}}$ receptors and anoctamins, hyperpolarize or depolarize the membrane potential [169]. When the intracellular $\mathrm{Cl}^{-}$ concentration is relatively high, the channel activation allows $\mathrm{Cl}^{-}$ions to diffuse to the outside of the cell and drives depolarization of the cell membrane, which typically occurs in DRG neurons $[169,170]$. An inflammatory soup containing micromolar $\mathrm{PGE}_{2}$ has been shown to cause even higher intracellular $\mathrm{Cl}^{-}$concentrations in rat DRG neurons by inversely regulating the protein levels of the two essential $\mathrm{Cl}^{-}$transporters that maintain $\mathrm{Cl}^{-}$concentration homeostasis in the following manner: increasing protein levels of the $\mathrm{Cl}^{-}$importer $\mathrm{Na}-\mathrm{K}-\mathrm{Cl}$ cotransporter 1 (NKCC1) and decreasing the levels of the $\mathrm{Cl}^{-}$exporter $\mathrm{K}-\mathrm{Cl}$ cotransporter 2 (KCC2) [171]. Those authors suggest that nociceptive signals caused by $\mathrm{Cl}^{-}$ currents could be augmented. However, a more recent study conducted by the Oh group demonstrated that Slc12a2 (which encodes NKCC1 protein)-null mice show no difference in the $\mathrm{PGE}_{2}$-induced potentiation of $\mathrm{GABA}_{\mathrm{A}}$-mediated nociception compared with wild type mice [38]. It remains controversial whether DRG express KCC2 and which KCC subtypes are predominantly expressed [172-177]. More thorough approaches, such as using specific PGs, precisely monitoring KCC protein levels, and screening the effective duration of their exposure for altering $\mathrm{Cl}^{-}$homeostasis could be required in the future.

\section{The effect of $P G E_{2}$ on hyperpolarization-activated cyclic nucleotide gated channels (HCNs)}

$\mathrm{HCN}$ ion channels are activated by hyperpolarized voltages or cAMP and lead to cation influx, depolarizing the membrane potential. Therefore, their activation increases neuronal excitability and, in particular, contributes to the elevation of action potential frequency [178]. Among the four isotypes, $\mathrm{HCN} 1$ and 2 appear to be highly expressed in DRG neurons [179-182]. Given their intrinsic sensitivity to cAMP, $\mathrm{HCNs}$ had been hypothesized to be activated by cAMP produced by $\mathrm{PGE}_{2}$ signaling, bypassing further signal transduction. Indeed, even before $\mathrm{HCN}$ gene identification, hyperpolarizationactivated cation current (Ih) in cultured nodose neurons was shown to be greatly enhanced by $\mathrm{PGE}_{2}$ exposure $[183,184]$. More than a decade later, the subtypes that are most reactive to $\mathrm{PGE}_{2}$ in DRG neurons were confirmed. An Hcn1 knockout study conducted by the McNaughton group demonstrated that HCN1, which was mainly expressed in large-diameter neurons, was activated by $\mathrm{PGE}_{2}$-produced $\mathrm{cAMP}$, and that this mechanism was at least partly responsible for cold allodynia caused by pSNL neuropathy [181]. Using Nav1.8-positive nociceptor-specific knockouts for Hcn2 (instead of global Hcn 2 knockouts, because those were extremely unhealthy), the same group further showed that HCN2 is activated in the same manner and contributes to heat, but not mechanical, hyperalgesia in a $\mathrm{PGE}_{2}$ injection model, carrageenan-inflammation model, and CCI neuropathy model [185].

Large-diameter $A \beta$ afferent neurons, which normally relay casual touch signals as mentioned above, can become hyper-excitable and take part in nociception in certain pathological conditions [186-188]. Such an event is one cause for mechanical allodynia, in which light touch stimuli are misinterpreted as painful. In this situation, $\mathrm{PGE}_{2}$ seems to play a role. A recent study found that COX-1-generated $\mathrm{PGE}_{2}$ sensitizes $\mathrm{A} \beta$ DRG neurons and eventually contributes to mechanical allodynia in a bee venom injection model with the ablation of TRPV1positive neurons [39]. The sensitizing mechanism appears to occur through up-regulated expression of 
HCN1 and 2. Consequently, Ih was significantly increased in the large-diameter neurons, and as a result, those neurons changed their action potential firing pattern from phasic to sustained. How the elevated $A \beta$ signals can be transmitted to the pain perception center remains as a current issue for further investigations [189].

\section{Reciprocal effects of $P G E_{2}$ and $B K$}

BK promotes inflammation and inflammatory pain by increasing vasodilation, vascular permeability, mediator synthesis, and nociceptor excitability [190]. In fact, numerous studies have hypothesized that $\mathrm{BK}$ and $\mathrm{PGE}_{2}$ interact closely in processing inflammatory pain. As a result, it is currently known that BK facilitates the production and release of $\mathrm{PGE}_{2}$, and that BK-induced nociception is also synergized by the addition of $\mathrm{PGE}_{2}$. Through the signal transduction and effector mechanisms listed above, $\mathrm{PGE}_{2}$ facilitates nociceptor excitation rather than directly causing action potentials in those neurons. BK-induced excitation is affected in the same way [191]. Interestingly, Smith and colleagues have mechanistically shown that this process may involve the mobilization of $\mathrm{Ca}^{2+}$, which is a central second messenger for $\mathrm{PGE}_{2}$ signal transduction [192]. In a subpopulation of capsaicin-responsive small-diameter DRG neurons, $\mathrm{PGE}_{2}$ increased intracellular $\mathrm{Ca}^{2+}$ in a manner that depended on the presence of extracellular $\mathrm{Ca}^{2+}$ [192]. Through this mechanism, pre-incubation with $\mathrm{PGE}_{2}$ potentiated a BK-induced intracellular $\mathrm{Ca}^{2+}$ increase and BK-evoked SP release in small-diameter nociceptors, as well as an increase in the number of BKresponsive neurons [192]. This sensitizing effect was reproduced by the application of bucladesine, a membrane-permeable cAMP analog, and the effect was suppressed by H89, a PKA inhibitor [192]. It is possible that the activities of voltage-gated $\mathrm{Ca}^{2+}$ channels or $\mathrm{Ca}^{2+}$-permeable TRPV1, all of which are effectors for $\mathrm{PGE}_{2}$ signaling, are positively modulated by PKA action that thereby contributes to $\mathrm{Ca}^{2+}$ influx. Thus, the critical point for signal merge appears to be an increase in intracellular $\mathrm{Ca}^{2+}$, which is also essential to BK-induced signal transduction. In the same study, $\mathrm{PGI}_{2}$ treatment exerted a similar effect on the $\mathrm{BK}$-induced $\mathrm{Ca}^{2+}$ increase, whereas $\mathrm{PGF}_{2 \alpha}$ treatment did not [192]. $\mathrm{PGE}_{2}$ elevated the magnitude of depolarization and increased the number of action potentials induced by BK [193]. Such $\mathrm{PGE}_{2}$-induced potentiation was independent of the concentration of NGF, which can also induce inflammatory pain and the hypersensitivity of somatosensory neurons [193, 194].

Several studies have emphasized that BK uses PGs for one of its final outcomes, pain induction. The COX signaling pathway appears to be required in developing BKinduced mechanical hypersensitivity [40, 195]. BK has been shown to lead to COX induction and this interestingly seems to be a transcellular process in which TNF $\alpha$ and other pro-inflammatory interleukins, including IL-1 $\beta$, IL-6, and IL-8, are sequentially secreted from neighboring cells, such as glia or macrophages [41, 196198]. It remains uncertain whether the final COX increase and PG secretion occur mainly in neuronal or nonneuronal components. Neuronal COX expression was once reported to be elevated later than the initial pain induction by BK [199]. Exposing cultured rat trigeminal or DRG neurons to BK for 30 min to $3 \mathrm{~h}$ in evoked $\mathrm{PGE}_{2}$ release from the neurons, which was completely blocked by COX inhibitors in two independent studies $[24,43]$. In both of those studies, B2 receptor activation appeared to be important to the secretory action.

\section{$P G E_{2}$-induced generation of neuropeptides and trophic factors}

$\mathrm{SP}$ is a peptidergic neurotransmitter released from a subset of $\mathrm{C}$-nociceptors and exacerbates inflammation and pain, as mentioned above [44]. The pro-inflammatory cytokine IL- $1 \beta$ has been shown to increase SP release by elevating COX-2 mRNA levels in rat DRG neurons [33]. Interestingly, $\mathrm{NO}$ facilitated IL-1 $\beta$-induced COX-2 elevation in rat DRG neurons in a manner independent of its typical downstream messenger cyclic guanosine monophosphate (cGMP), and eventually facilitated SP release from these neurons [34]. The pharmacological antagonism of EP1 and EP2 receptors using AH-6809 showed no effect on $\mathrm{PGE}_{2}$-induced $\mathrm{SP}$ release from isolated rat renal somatosensory nerves, whereas the EP4 antagonists L161982 and $\mathrm{AH}-23848$ blocked it [200]. $\mathrm{PGE}_{2}$ not only contributes to SP release, but also promotes the expression of its receptor (SPR, also known as tachykinin receptor 1 or neurokinin 1 receptor) in cultured rat DRG neurons, and this elevated expression likely depends on the cAMP-PKA pathway [201]. The same study functionally demonstrated that the increase of intracellular $\mathrm{Ca}^{2+}$ in DRG neurons caused by SP exposure was significantly enhanced by $\mathrm{PGE}_{2}$ [201].

CGRP serves roles similar to those of SP in pain development [202]. $\mathrm{PGE}_{2}$-mediated cAMP signaling also positively regulates the release of CGRP [78]. In cultured DRG neurons, exposure to $\mathrm{PGE}_{1}$ or $\mathrm{BK}$ dose-dependently increased the expression and release of CGRP [42]. Preincubation with the COX inhibitor indomethacin suppressed BK-mediated CGRP release but not $\mathrm{PGE}_{1}$-induced CGRP release, indicating that COX-mediated PG production and possibly its autocrine and/or paracrine actions contribute to CGRP release from DRG neurons in BKexposed conditions [42]. Morphine treatment, despite being known as a potent analgesic strategy, may exacerbate pain, such as when it is used as a preventive treatment for postoperative hyperalgesia [203]. Tumati and colleagues suggested a potential mechanism for this process by which 
sustained morphine treatment promotes $\mathrm{PGE}_{2}$-mediated CGRP release from somatosensory neurons [204].

Numerous studies have shown that up-regulated brainderived neurotrophic factor (BDNF) in DRG neurons and the spinal cord contributes to the pathogenesis of chronic pain [205-209]. In a pSNL neuropathic pain model in rats, the injection of a COX-2 inhibitor (NS-398) or EP4 antagonist (AH23848) into the L4-L6 DRG lowered the injuryderived level of BDNF and improved mechanical hypersensitivity in a dose-dependent manner [35]. The same group replicated the paradigm by using explant cultures of the DRG, showing that a stabilized $\mathrm{PGE}_{2}$ analog, dimethyl $\mathrm{PGE}_{2}\left(\mathrm{dmPGE}_{2}\right)$, significantly elevated the BDNF level, dependent on EP1 and EP4 activation. Therefore, they suggested that nerve injury-derived $\mathrm{PGE}_{2}$ may facilitate BDNF production, contributing to neuropathic pain [35].

\section{The effect of $P G E_{2}$ on neuritogenesis}

$\mathrm{PGE}_{2}$ plays a role in neurite outgrowth. Studies have elucidated $\mathrm{PGE}_{2}$-induced neurite elongation through EP2 or EP4 activation using neuronal cell lines, such as human neuroblastoma SK-N-BE(2) C cells, mouse neuroblastoma NG108-15 cells, somatosensory neuron-like ND7/23 cells, and motor neuron-like NSC-34 cells [210-213]. In addition, intraperitoneal injection of COX inhibitors, such as meloxicam and nimesulide, reduced adult neurogenesis in the hippocampus and the subventricular zone [30]. Indeed, treatment of cultured mouse DRG neurons with $\mathrm{PGE}_{2}$ has also been shown to promote neuritogenesis and axonal transport in an EP2 and cAMP-dependent manner [214]. It can be hypothesized that an upstream trophic factor could be using PGsignaling for this neuritogenesis, and vascular endothelial growth factor (VEGF) has been proposed as a candidate [215]. Cheng et al. demonstrated that VEGF stimulates COX-mediated production of $\mathrm{PGE}_{2}$ through the activation of one of its receptors, neuropilin-1 which is highly expressed in DRG neurons; they also showed that VEGF leads to the production of $\mathrm{PGI}_{2}$ [25]. VEGF-induced growth cone formation was abrogated by treatment with COX inhibitors, including indomethacin, SC-560 (for COX-1 inhibition), and NS-398 (for COX-2 inhibition). It remains unclear which EP receptors are critical and even which PGs are the best regulators for this process, because specific EP agonists were not successful in replicating this effect, whereas many endogenous prostaglandins were effective in rescuing growth cone collapse [25]. In a different study, however, the EP1/EP3 receptor agonist sulprostone was shown to cause retraction of the neurites of DRG neurons in a Rho-kinase-dependent fashion [108]. These morphologic theories await further investigations into how much the PG mechanisms contribute to pathological increases in nociceptor innervation and the following exacerbation of pain.

\section{$\mathrm{PGI}_{2}$}

$\mathrm{PGI}_{2}$, also known as prostacyclin, is formed from $\mathrm{PGH}_{2}$ by the action of prostacyclin synthase (Fig. 1). It was first identified in vascular endothelial cells, where it causes vasodilation and inhibits platelet aggregation [216]. The evidence for the pro-nociceptive action of $\mathrm{PGI}_{2}$ has been accumulated as follows.

\section{$\mathrm{PGI}_{2}$ effects on nociceptive responses}

Similar to the effects of $\mathrm{PGE}_{2}$, intradermal injection of $\mathrm{PGI}_{2}(1 \mu \mathrm{g})$ in rodent hind paws decreased the nociceptive threshold in response to mechanical stimuli, which was found to involve cAMP signaling in nociceptors [217]. The intraperitoneal injection of carbaprostacyclin $\left(\mathrm{CPGI}_{2}\right)$, a stable prostacyclin analog, in sciatic nerve-transected rats increased the ectopic activity of DRG and dorsal horn neurons, suggesting that the generation of $\mathrm{PGI}_{2}$ might contribute to neuropathic pain [218]. Consistently, treatment with cicaprost, a $\mathrm{PGI}_{2}$ synthetic analog, has been shown to robustly increase cAMP production in rat adult DRG neurons to an even greater extent than $\mathrm{PGE}_{2}$ treatment [108]. That author hypothesized that the prostacyclin receptor might be responsible solely for elevating cAMP generation, whereas $\mathrm{PGE}_{2}$ might simultaneously activate multiple types of EPs, one of which uses the Goi pathway and leads to a decrease in the cAMP level.

\section{The $\mathrm{PGI}_{2}$ receptor (IP) in nociceptors}

One type of IP is conserved in mammals. mRNA transcripts for the IP-encoding gene Ptgir were readily detected in both small- and large-sized neurons in the L6 and S1 DRG of rodents [77, 219]. IP activation recruits the Gos protein, activates adenylyl cyclase, and raises intracellular cAMP levels in a manner identical to that of the EP2, EP4, and DP1 receptors [220]. A genetic approach that generated mice deficient in Ptgir (which encodes IP protein) enriched the body of information about the roles of IP in pain and inflammation [221]. The intradermal injection of $\mathrm{PGI}_{2}$ enhanced BKinduced vascular permeability in wild-type mice, but not in Ptgir-deficient mice [221]. The Ptgir-ablated mice exhibited decreased edema formation when inflamed by carrageenan and reduced acetic acid-evoked writhing, compared with wild-type mice [221]. When $\mathrm{PGI}_{2}(2 \mu \mathrm{g})$ was injected intraperitoneally, $60 \%$ of the wild-types writhed, whereas the knockouts displayed no such nociceptive response [221]. Pharmacological approaches have shown consistent results. In DRG neurons, IP activation by its agonists such as cicaprost and iloprost heightened adenylyl cyclase activity [107, 219]. The cAMP accumulation caused by this IP activation led to the potentiation of capsaicin-, ATP-, and $\mathrm{KCl}$-induced SP release in DRG neurons [219]. On the other hand, the application of an IP antagonist, 2-[4-(1H-indol-4-yloxymethyl)benzyloxycarbonylamino]-3-phenyl-propionic acid, reversed the sensitized SP release [222]. More recently, Ng et al. have 
shown that the expression and downstream signaling cascade of IP were commonly conserved in somatosensory neurons and glial cells of DRG [113].

\section{TRPV1 potentiation by $\mathrm{PGI}_{2}$}

As briefly mentioned in the $\mathrm{PGE}_{2}$ section above, $\mathrm{PGI}_{2}$ greatly potentiates TRPV1 activity. Pitchford et al. initially described the facilitation of TRPV1-mediated currents in DRG neurons upon $\mathrm{PGI}_{2}$ exposure, and knowledge about the details of signal transduction between IP activation and TRPV1 activation was enriched by Moriyama et al. [149, 151]. Briefly, IP activation by nanomolar amounts of $\mathrm{PGI}_{2}$ stimulates the Gos-coupled adenylyl cyclase-PKA pathway in a relatively slow fashion (six minutes or longer), whereas micromolar concentrations of $\mathrm{PGI}_{2}$ additionally activate the Goq-coupled PLC-PKC pathway on a fast time scale ( one minute) [151]. Both kinases phosphorylate TRPV1, leading to its heightened activity not only in response to its binding to ligands such as capsaicin, but also to heat and eventually contributing to TRPV1-mediated pain exacerbation.

\section{5-Deoxy- $\Delta 12,14-P G J_{2}$ (15d-PGJ $\left.{ }_{2}\right)$}

$\mathrm{PGD}_{2}$ is further dehydrated into J series PGs, all of which contain a cyclopentenone ring [47]. The dehydration of $\mathrm{PGD}_{2}$ is a non-enzymatic process and consecutively produces $\mathrm{PGJ}_{2}$ (from the first dehydration) and $15 \mathrm{~d}-\mathrm{PGJ}_{2}$ (from the further dehydration and isomerization of $\mathrm{PGI}_{2}$ ) (Fig. 1). The terminally dehydrated form $15 \mathrm{~d}-\mathrm{PGJ}_{2}$ can activate DP receptors, and also exert its actions by binding directly to other heterogeneous molecular targets such as the ion channel and nuclear receptor, as described below (Table 3).

\section{TRPA 1 activation and desensitization by $15 \mathrm{~d}-\mathrm{PG} \mathrm{J}_{2}$}

Unlike TRPV1, for which most of the specific chemical activators mimic non-covalent capsaicin binding to the intracellular linker between the fourth and fifth transmembrane domains, the principle mode of ligand binding to TRPA1 is a covalent interaction [230-232]. When they can access several critical cysteine and/or lysine residues of the N-terminal cytoplasmic tail of the TRPA1 protein, electrophilic chemicals covalently bind to those residues, which eventually opens the channel pore.

$15 \mathrm{~d}-\mathrm{PG} \mathrm{J}_{2}$, which has a highly reactive $\alpha \beta$-unsaturated carbonyl carbon, follows this covalent binding rule. In cultured DRG neurons, $20 \mu \mathrm{M} 15 \mathrm{~d}-\mathrm{PGI}_{2}$ raised intracellular $\mathrm{Ca}^{2+}$ levels in AITC-responsive (presumably TRPA1-positive) DRG neurons, which was undetectable in DRG neurons from Trpa1-deficient mice [223]. In both whole cell and inside-out patch clamp modes, 15d$\mathrm{PGJ}_{2}$ evoked inward currents in TRPA1-overexpressing cells, suggesting that it activates TRPA1 in a membranedelimited manner [223-225, 233, 234]. Two N-terminal cysteine residues (Cys421 and Cys621) of TRPA1 were determined to be the most critical for channel gating by $15 \mathrm{~d}-\mathrm{PGJ} \mathrm{J}_{2}$ [233]. On the other hand, $15 \mathrm{~d}-\mathrm{PGJ} \mathrm{J}_{2}$ is inert to other nociceptive TRPs such as TRPV1 and melastatin subtype 8 of TRP (TRPM8) [223, 225]. In a nonenzymatic manner similar to that in the production of the $\mathrm{I}$ series $\mathrm{PG}, \mathrm{PGA}_{1}$ and $\mathrm{PGA}_{2}$ are produced from $\mathrm{PGE}_{2}$ dehydration, and 8-iso- $\mathrm{PGA}_{2}$ comes from the dehydration of 8-iso-PGE $\mathrm{P}_{2}$. These three dehydrated substances also contain an $\alpha \beta$-unsaturated carbonyl moiety in their cyclopentenone rings, and these electrophilic carbons can react with TRPA1 cysteines in the same covalent fashion, resulting in TRPA1 activation [224, 234].

Such in vitro reactivity was successfully extrapolated to the in vivo and circuit levels. The hind paw intraplantar administration of $15 \mathrm{~d}-\mathrm{PGJ}_{2}$ evoked nociceptive responses, including licking, biting, and flinching, in wildtype mice, whereas those responses were scarcely detected in Trpa1-deficient mice [223-225]. Cyclopentenone PGs robustly stimulated SP and CGRP release from nociceptors in the dorsal spinal cord and caused the expression of the c-fos gene, a marker of neuronal excitation, in dorsal spinal neurons [224].

Interestingly, this TRPA1-mediated mechanism also appears to be involved in the pain relief caused by $15 \mathrm{~d}$ $\mathrm{PGJ}_{2}$ treatment, which was once shown to reverse inflammatory pain in a CFA-injected animal model. Intraplantar application of $15 \mathrm{~d}-\mathrm{PGJ}_{2}$ to mouse hind paws reduced mechanical hypersensitivity in that model, but the effect was not observed in Trpa1-deficient mice [226]. The authors suggested that the analgesic effect may be due to subsequent desensitization of TRPA1 followed by $15 \mathrm{~d}-\mathrm{PGJ}_{2}$-induced TRPA1 activation [226]. The analgesic effect of $15 \mathrm{~d}-\mathrm{PGJ}_{2}$ and its potential molecular mechanisms have also been of recent interest in another context, as follows.

\section{Peroxisome proliferator-activated receptor $\gamma$ (PPAR $\gamma)$ activation by $15 \mathrm{~d}-\mathrm{PG} \mathrm{J}_{2}$}

When activated by their ligands, which are mostly lipid metabolites, the PPARs can alter multiple physiological functions, including glucose absorption, lipid balance, cell growth, and inflammation, by inducing transcriptional regulation [235]. Interestingly, PGDs and cyclopentenone PGs, such as $15 \mathrm{~d}-\mathrm{PGJ} \mathrm{J}_{2}, \mathrm{PGJ}_{2}, \mathrm{PGA}_{1}$, and $\mathrm{PGA}_{2}$ can activate PPAR [236-238]. Among those examples, $15 \mathrm{~d}-\mathrm{PGJ} \mathrm{J}_{2}$ has been investigated in the context of pain modulation. Intraplantar injection of $15 \mathrm{~d}-\mathrm{PGJ}_{2}$ has been shown to diminish the mechanical hypersensitivity of rat hind paws inflamed by carrageenan or $\mathrm{PGE}_{2}$ [228]. This effect was reduced by treatment with the PPAR $\gamma$ antagonist, GW9662 [228]. Interestingly, intra-DRG injection of $15 \mathrm{~d}-\mathrm{PGJ}_{2}$ did not successfully relieve this mechanical hypersensitivity [228]. The same group also 
Table 3 Functional effects of peripherally injected 15d-PGJ2 on nociceptive responses

\begin{tabular}{|c|c|c|c|c|c|}
\hline Animal models & Injection & Dose & Effects & Remarks & References \\
\hline Normal mouse & Intraplantar & $\begin{array}{l}32 \mathrm{nmol} / \\
25 \mu \mathrm{l}\end{array}$ & 个Licking, flinching & Disappeared in TRPA $1^{-/-}$ & [223] \\
\hline Normal mouse & Intraplantar & $\begin{array}{l}15 \mathrm{nmol} / \\
20 \mu \mathrm{l}\end{array}$ & 个Licking, lifting & Disappeared in TRPA1 ${ }^{-/-}$ & [224] \\
\hline Normal mouse & Intraplantar & $\begin{array}{l}15 \mathrm{nmol} / \\
10 \mu \mathrm{l}\end{array}$ & 个Licking, lifting & Disappeared in TRPA1 ${ }^{-/-}$ & {$[225]$} \\
\hline $\begin{array}{l}\text { Complete Freund's } \\
\text { adjuvant injected } \\
\text { mouse }\end{array}$ & Intraplantar & $\begin{array}{l}1.5 \text { or } 15 \\
\mathrm{mM} / 10 \mu \mathrm{l}\end{array}$ & $\begin{array}{l}\downarrow \text { Mechanical } \\
\text { hypersensitivity }\end{array}$ & Disappeared in TRPA $1^{-/-}$ & {$[226]$} \\
\hline $\begin{array}{l}\text { Sciatic nerve-injured } \\
\text { rat }\end{array}$ & Intrathecal & $\begin{array}{l}50- \\
200 \mu \mathrm{g} / \\
15 \mu \mathrm{l}\end{array}$ & $\begin{array}{l}\downarrow \text { Mechanical and } \\
\text { cold hypersensitivity }\end{array}$ & Attenuated by PPARy antagonist & {$[227]$} \\
\hline $\begin{array}{l}\text { Sciatic nerve-injured } \\
\text { rat }\end{array}$ & $\begin{array}{l}\text { Intraperitoneal } \\
\text { lintracerebroventricular }\end{array}$ & $100 \mu \mathrm{g}$ & $\begin{array}{l}\leftrightarrow \text { Mechanical and } \\
\text { cold hypersensitivity }\end{array}$ & & {$[227]$} \\
\hline $\begin{array}{l}\text { Carrageenan-induced } \\
\text { inflamed rat }\end{array}$ & Intraplantar & $\begin{array}{l}30-300 \\
\mathrm{ng} / 100 \mu \mathrm{l}\end{array}$ & $\begin{array}{l}\downarrow \text { Mechanical } \\
\text { hypersensitivity }\end{array}$ & Attenuated by PPARY antagonist & [228] \\
\hline $\begin{array}{l}\text { Formalin-induced TMJ } \\
\text { rat }\end{array}$ & $\begin{array}{l}\text { Into } \\
\text { temporomandibular } \\
\text { joint }\end{array}$ & $\begin{array}{l}100 \mathrm{ng} / \\
50 \mu \mathrm{l}\end{array}$ & $\begin{array}{l}\downarrow \text { Mechanical } \\
\text { hypersensitivity }\end{array}$ & Attenuated by PPARy antagonist & {$[228]$} \\
\hline $\begin{array}{l}\text { Formalin-induced } \\
\text { inflamed rat }\end{array}$ & Intraplantar & $\begin{array}{l}100 \mathrm{ng} / \\
50 \mu \mathrm{l}\end{array}$ & $\begin{array}{l}\leftrightarrow \text { Mechanical and } \\
\text { cold hypersensitivity }\end{array}$ & & {$[228]$} \\
\hline $\begin{array}{l}\mathrm{PGE}_{2} \text {-induced inflamed } \\
\text { rat }\end{array}$ & Intraplantar & $\begin{array}{l}30-300 \\
\mathrm{ng} / 50 \mu \mathrm{l}\end{array}$ & $\begin{array}{l}\downarrow \text { Mechanical } \\
\text { hypersensitivity }\end{array}$ & $\begin{array}{l}\text { Attenuated by PPAR, Opioid receptor, Nitric oxide/ } \\
\text { cGMP/PKG)/K }{ }_{\text {ATP pathway antagonists }}\end{array}$ & [228] \\
\hline $\begin{array}{l}\mathrm{PGE}_{2} \text {-induced inflamed } \\
\text { rat }\end{array}$ & Intraganglionic & $\begin{array}{l}100 \mathrm{ng} / \\
10 \mu \mathrm{l}\end{array}$ & $\begin{array}{l}\leftrightarrow \text { Mechanical and } \\
\text { cold hypersensitivity }\end{array}$ & & [228] \\
\hline $\begin{array}{l}\text { TNFa induced } \\
\text { inflamed rat }\end{array}$ & Intraplantar & $\begin{array}{l}100 \mathrm{ng} / \\
100 \mu \mathrm{l}\end{array}$ & $\begin{array}{l}\downarrow \text { Mechanical } \\
\text { hypersensitivity }\end{array}$ & & {$[228]$} \\
\hline $\begin{array}{l}\text { Formalin-induced TMJ } \\
\text { rat }\end{array}$ & $\begin{array}{l}\text { Into } \\
\text { temporomandibular } \\
\text { joint }\end{array}$ & $\begin{array}{l}1-100 \\
\mathrm{ng} / 50 \mu \mathrm{l}\end{array}$ & $\begin{array}{l}\downarrow \text { Mechanical } \\
\text { hypersensitivity }\end{array}$ & $\begin{array}{l}\text { Attenuated by PPARy antagonist, Opioid receptor, } \\
\text { (Nitric oxide/cGMP/PKG)/K }{ }_{\text {ATP }}^{+} \text {pathway antagonists }\end{array}$ & [229] \\
\hline
\end{tabular}

used formalin- and serotonin-induced temporomandibular joint (TMJ) pain and demonstrated that administration of $15 \mathrm{~d}-\mathrm{PGJ}_{2}$ into the TMJ suppressed hypernociception $[228,229]$. The authors' pharmacological explorations of the downstream mechanisms of this $15 \mathrm{~d}$ $\mathrm{PGJ}_{2}$ signaling suggested that non-neuronal cells, such as macrophages, and $\mathrm{k}$ and $\delta$ opioid receptors could contribute to its analgesic mechanisms.

In a different study, Churi and colleagues demonstrated the presence of PPARY mRNA and proteins in the dorsal horn of the rat spinal cord [227]. The intrathecal injection of endogenous and synthetic PPAR $\gamma$ ligands (15d-PGJ $)_{2}$ or rosiglitazone) dose-dependently alleviated the mechanical and cold hypersensitivity of rats with sciatic nerve injury [227]. The analgesic effects of $15 \mathrm{~d}-\mathrm{PGJ}_{2}$ and rosiglitazone were blunted by the coadministration of a PPARy antagonist (bisphenol A diglycidyl ether, also known as BADGE). In the same study, intraperitoneal and intracerebroventricular injections of PPAR $\gamma$ agonists failed to reduce mechanical and cold hypersensitivities [227]. Future studies will quantitatively clarify whether TRPA1 activation-mediated pain generation, TRPA1 desensitization-mediated pain reduction, or PPAR $\gamma$-mediated pain reduction predominates in physiological and pathological states. It also must be determined whether $15 \mathrm{~d}-\mathrm{PGJ}_{2}$ displays differential effects on the peripheral pain pathway depending on its location and concentration.

\section{Thromboxane $\mathrm{A}_{\mathbf{2}}\left(\mathrm{TXA}_{\mathbf{2}}\right)$}

$\mathrm{TXA}_{2}$, generated by TXA ${ }_{2}$ synthase 1 (TBXAS1) directly from $\mathrm{PGH}_{2}$, is an unstable prostanoid with a chemical half-life of about $30 \mathrm{~s}$ and is further spontaneously converted into $\mathrm{TXB}_{2}$, an inactive metabolite [239, 240] (Fig. 1). $\mathrm{TXA}_{2}$ activates its specific Goq-protein coupled receptor TP (thromboxane receptor), which initiates the PLC signal transduction pathway [241] (Hirata et al., 1991). TXA 2 has been intensely investigated with regard to its function in platelet aggregation and smooth muscle contraction [242-244]. Recent $\mathrm{TXA}_{2}$ studies have expanded into its roles in other physiological and pathological circumstances such as cancer metastasis, immune responses, and asthma (See review: [244]). Several studies have also looked into its role in visceral sensory and somatosensory contexts. 


\section{Nociceptor excitation by TXA $A_{2}$ mimetics}

Due to the extremely short half-life of TXA 2 , the TXA mimetic U46619 is often used to study the roles of TXA in sensory nerve-mediated responses. The infusion of U46619 into vagal $C$-fibers innervating the lung elicited massive firing of those nerves $[245,246]$. This excitation may help explain how $\mathrm{TXA}_{2}$ caused the reflexive pulmonary hypertension and rapid shallow breathing observed in previous studies and indicates that vagal nerve interaction with $\mathrm{TXA}_{2}$ may importantly contribute to cardiorespiratory feedback regulation [245-247]. Since that study, diverse measures from different animal models have confirmed this U46619 response led by the excitation of autonomic C-fibers, such as those associated with the vagal reflex-mediated knee-jerk reflex of cats, tachypnea and bradycardia of rabbits, and chemoreceptor activation in rats [248-251]. U46619 could also stimulate somatosensory nociceptors. Systemic injection of U46619 through the abdominal aorta of cats led to increases in the baseline impulses of action potential generated from a subset of A $\delta$-fibers ( 30\%) and C-fibers $(\sim 60 \%)$ both of which innervate the hind limbs [252-254].

The use of a TP receptor antagonist may help determine the actions of endogenous $\mathrm{TXA}_{2}$ and it has also been tried in the vagal components [255]. Treatment with the selective TP antagonist BM13177 attenuated the increased activity of cardiac sensory afferents in ischemic cats [255]. The injection of U46619 into the left atrium further excited cardiac afferents in a dose-dependent manner, which was suppressed by treatment with BM13177 or the inhibitor, PKC-(19-36). Therefore, these findings suggest that endogenous $\mathrm{TXA}_{2}$ generated in ischemic conditions may stimulate cardiac sensory afferents through a TP-mediated PLC-PKC signal transduction pathway (Fig. 3).

\section{TP expression in nociceptors}

Tbxa2r mRNA transcripts for TP expression were detected in a single cell RT-PCR analysis of neurons cultured from nodose ganglia (which contain the cell bodies of vagal afferents) and thoracic DRG excised from adult rabbits [256, 257]. The TP-positive population was slightly larger in the nodose neurons $(\sim 18 \%)$ than in the DRG neurons $(\sim 12 \%)$, and more than half of those neurons were also TRPV1-positive [257]. Using immunohistochemistry in mice, Andoh and colleagues showed that not only the small-to-medium-sized DRG neurons that innervate the skin, but also epidermal keratinocytes express TPs [258]. Whereas most keratinocytes expressed both TBXAS1 and TP, $78 \%$ of small-sized neurons, $48 \%$ of medium-sized neurons, and $13 \%$ of large-diameter neurons exhibited TPimmunoreactivity while being negative for TBXAS1, which indicates that $\mathrm{TXA}_{2}$ is generated mostly from keratinocytes and may interact with TP in keratinocytes and nociceptors in autocrine and paracrine manners [258]. Those authors looked further into that paradigm in the context of itchiness. The intradermal injection of U46619 caused scratching behavior in ICR mice, which was attenuated by treatment with the TP receptor antagonist ONO-3708 [258]. Such U46619-induced scratching behaviors were almost absent in the TP receptor-deficient mice [258]. In cultured mouse DRG neurons and keratinocytes, Andoh and colleagues confirmed that U46619 can induce increases in intracellular $\mathrm{Ca}^{2+}$ through TP receptor signaling, which possibly indicates that Goq-PLC-mediated $\mathrm{Ca}^{2+}$ mobilization contributes to the phenotype [258]. These findings suggest that TP activation by $\mathrm{TXA}_{2}$ involving keratinocytes and DRG neurons may compose an itch-induction mechanism.

\section{Limitations in the current knowledge about PGs}

Despite the details that have accumulated about the pronociceptive mechanisms of PGs, those still remain to be further systematized and extended. Although there has already been a clinically available series of PG-modulable analgesic strategies, they are not now considered quite successful, particularly in treating neuropathic pain [259]. This situation requires us to consider how immature the current knowledge is and what remains to be solved. For example, a more systematic view likely needs to be constructed, embracing the diverse and newly suggested participant molecules in PGassociated cellular processes and quantifying their contributions to final pain outcomes. In addition, a circuit-specific inflammatory etiology involving a multitude of PGs may need to be monitored precisely because functional plasticity in the somatosensory circuit is likely a central cause of chronic pain. More information may also be required on how different PG contributions to pain severity vary chronologically during its exacerbation, since some PGs might be more important at the onset of the plastic changes in the pain circuit and others at the maintenance stage. The effects of some clinically available COX inhibitors have been highlighted in neuropathic animal models as mentioned above. However, considering the high doses used in most of those studies, their efficacy and potency do not seem to be realized for the human clinical setting. Possibly more potent but, to avoid adverse effects in other tissues, highly specific strategies to the somatosensory circuit may have next opportunities. It may also implicate the potential diversity of human pain mechanisms that can hardly be covered with a limited number of the current animal models. More fundamentally, considering the possible species differences, a reappraisal of the current models, the development of newly optimized ones on the mechanistic basis, and the standardization of humanized platforms may be required [260]. Collectively, overcoming such existing inadequacies may could enable new possibilities for clinical applications. 
COX produces not only PGs but also resolvent lipids such as resolvins, maresin, and neuroprotectins [261, 262]. The resolvent lipids promote the termination of inflammation by regulating macrophages, monocytes, and microglia, and they also directly mitigate nociceptor excitability. Thus, the outcomes of their possible reduction by COX inhibition may need to be taken into account. In this regard, further downstream targeting is likely to be more effective in the peripheral somatosensory system, while causing less disturbance to the endogenous resolution mechanism by, for example, selectively blocking pro-nociceptive EP2, EP4, DP1, and IP receptors or selectively activating EP3 and DP2 in nociceptors. Such receptor specific-protocols are becoming popular in various biomedical fields, including not only pain-related diseases, but also cancer and asthma [263, 264]. Quantitative information about which PGs and receptors cause the predominant outcomes can help in filtering more appropriate strategies. For example, DP2 activation can even reverse the EP-mediated excitation of DRG neurons [265]. On the other hand, DP2 was once shown to contribute relatively less predominantly than DP1 to modifying TTX-R activity compared to DP1, as mentioned above [115]. Despite not being limited to the status of nociceptor excitability, but reflecting their central contributions together, EP and DP knockouts were compared in a pain study, which indicated that EP4 activation may be more important in heat pain, EPland 3 seem to be involved in heat pain reduction, and EP2 and DP1 may contribute to formalin-induced pain [266].

Understanding farther downstream signaling might also be informative in building therapeutic hypotheses. As shown in the reciprocal relationship between PGs and BK, certain merge points present within a multitude of signaling cascades that are initiated by different but comparably important inflammatory pain mediators can be hypothesized as bottlenecks to gain a heightened nociception. Intracellular $\mathrm{Ca}^{2+}$, a common intracellular messenger in $\mathrm{PGE}_{2}$ and $\mathrm{BK}$-induced excitation, has also been shown to be important in the potentiation of the trigeminal $\mathrm{PGE}_{2} /$ BK response through Y2 neuropeptide Y receptor activation [267]. Histamine-induced rat DRG excitation is potentiated by $\mathrm{PGE}_{2}$ [268]. An influx of extracellular $\mathrm{Ca}^{2+}$ was raised as a key mechanism for the initiation of this potentiation [268], but for the $\mathrm{Ca}^{2+}$ carrying targets involved in this mobilization, we currently know only the molecules with less tissue specificity. Because this limited state of knowledge about downstream signaling makes therapeutic translation stay immature, future exploration is needed to create a comprehensive list of nociceptor-specific candidates for merger contributors.

The processes leading to PG breakdown have not been well elucidated in pain research investigating PG-associated mechanisms. The balance between the rates of PG production and degradation might affect pain states, because it determines whether the concentration of PGs reaches an effective window for inducing receptor activation and pain signals. Two enzymes that directly metabolize $\mathrm{PGE}_{2}$ and $\mathrm{TXB}_{2}$, respectively, have been shown: 15-hydroxyprostaglandin dehydrogenase (15-PGDH also known as HPGD) and 11-hydroxythromboxane $\mathrm{B}_{2}$ dehydrogenase (11TXB2DH) [269]. Because TXA $_{2}$ is the thromboxane most important in pro-nociception but is chemically labile, PG-degrading enzymes might be more critical in pain modulation than thromboxane-degrading ones. It can be hypothesized that enhancement of 15PGDH could decrease the concentration of PG, helping to normalize nociceptor excitability. Inhibition of the same enzyme could cause an opposite result. Currently, only one inhibitor is available, and it has recently been studied in the regeneration field. The inhibitor SW033291 has been demonstrated to effectively raise tissue-wide levels of PG and ultimately contribute to regeneration [270]. It might be interesting to explore how it affects inflammation and pain states in the nervous system.

\section{Perspectives and conclusion}

This review has highlighted the roles of arachidonic acid-derived PGs in nociception relayed by the peripheral somatosensory system. The current enlargement of knowledge may promote the design of a variety of antinociceptive strategies by surgically modulating specific PG actions. Such achievements may help to overcome the comparatively narrow focus and reliance on COX inhibition for pain control. Because a number of steps in the PG-mediated pain induction mechanisms remain less studied, their clarification may need to precede devising therapeutic tools targeting PGs in nociceptors. Pain diseases are diverse. The modulation of a PGrelated molecule must be mechanistically assessed to determine which severity, chronicity, inflammatory phase, and phenotype is more sensitive to it. Trigeminal mechanisms that, while not fully introduced here, operate similarly to the peripheral somatosensory circuit, appear to crucially use PG-mediated signaling in headaches, migraine pain, and meningeal neurogenic inflammation [271]. Recent progress in that field could be useful in determining therapeutic directions $[68,272-276]$. The PGs listed here are only the primary products enzymatically processed from the arachidonic acid- $\mathrm{PGH}_{2}$ axis. The effects on nociceptors of non-enzymatic products, including 12-hydroxyheptadecatrienoic acid, further metabolized substances like $\mathrm{PGF}_{1 \alpha}$, or other polyunsaturated fatty acid-derived PGs outside that axis also need to be examined in the future and compared with those described above. Such future efforts will provide a full picture of the mechanisms underlying somatosensory excitation and widen the pool for painkilling targets. 


\section{Abbreviations}

15-PGDH: 15-hydroxyprostaglandin dehydrogenase; AHP slow: Slow spike after-hyperpolarization; AITC: Allyl isothiocyanate; AKAP150: A-kinase anchoring protein 150; BDNF: Brain-derived neurotrophic factor; BK: Bradykinin; CCl: Chronic constriction injury; CFA: Complete Freund's adjuvant; CGRP: Calcitonin gene-related peptide; COXs: Cyclooxygenases; DRG: Dorsal root ganglia; HCN: Hyperpolarization-activated cyclic nucleotide gated channel; H-PGDS: Hematopoietic PGD synthase; IB4: Isolectin B4; Ih: Hyperpolarization-activated cation current; $\mathrm{K}_{\mathrm{Ca}}: \mathrm{Ca}^{2+}$-activated $\mathrm{K}^{+}$channel; KCC: K-Cl cotransporter; L-NMMA: $N^{G}$-monomethyl-L-arginine; LPGDS: Lipocalin-type PGD synthase; LPS: Lipopolysaccharide; mPGES1: Microsomal PGES-1; NGF: Nerve growth factor; NKCC: Na-K-Cl cotransporter 1; ODN: Oligodeoxynucleotide; PGES: $\mathrm{PGE}_{2}$ synthase; PGs: Prostaglandins; PPARY: Peroxisome proliferator-activated receptor $\gamma$; pSNL: Partial sciatic nerve ligation; RT-PCR: Reverse transcription-polymerase chain reaction; SP: Substance P; SPR: Substance P receptor; TBXAS1: TXA 2 synthase 1; TMJ: Temporomandibular joint; TNF: Tumor necrosis factor; TRP: Transient receptor potential; TTX: Tetrodotoxin; TTX-R: Tetrodotoxinresistant voltage-gated $\mathrm{Na}^{+}$channel; TTX-S: Tetrodotoxin-sensitive voltagegated $\mathrm{Na}^{+}$channel; TX: Thromboxane; VEGF: Vascular endothelial growth factor

\section{Acknowledgements}

Not applicable.

\section{Authors' contributions}

YJ and SWH conceived the idea. MK and SWH reviewed the concept of studies. YJ wrote the preliminary draft and SWH and MK wrote the manuscript. All authors read and approved the final manuscript.

\section{Funding}

This work was supported by grants from the National Research Foundation of Korea (2017R1A2B2001817, 2017M3C7A1025600, and 2019R1A4A1029000).

\section{Availability of data and materials}

Not applicable.

\section{Ethics approval and consent to participate}

Not applicable.

\section{Consent for publication}

All the authors consent to submit and publish this manuscript.

\section{Competing interests}

The authors declare that they have no competing interests.

\section{Author details}

'Department of Psychiatry and Program in Neuroscience, McLean Hospital, Harvard Medical School, Belmont, MA 02478, USA. ${ }^{2}$ Department of Biomedical Engineering, Hanyang University, Seoul 04763, South Korea. ${ }^{3}$ Department of Biomedical Sciences, Korea University, Seoul 02841, South Korea. ${ }^{4}$ Department of Physiology, College of Medicine, Korea University, Seoul 02841, South Korea.

Received: 20 August 2019 Accepted: 6 January 2020

Published online: 22 January 2020

\section{References}

1. Dennis EA, Norris PC. Eicosanoid storm in infection and inflammation. Nat Rev Immunol. 2015;15:511-23.

2. Petho G, Reeh PW. Sensory and signaling mechanisms of bradykinin, eicosanoids, platelet-activating factor, and nitric oxide in peripheral nociceptors. Physiol Rev. 2012;92:1699-775.

3. Straus DS, Glass CK. Cyclopentenone prostaglandins: new insights on biological activities and cellular targets. Med Res Rev. 2001;21:185-210.

4. Breyer RM, Bagdassarian CK, Myers SA, Breyer MD. Prostanoid receptors: subtypes and signaling. Annu Rev Pharmacol Toxicol. 2001;41:661-90.

5. Kawamura M, Inaoka H, Obata S, Harada Y. Why do a wide variety of animals retain multiple isoforms of cyclooxygenase? Prostaglandins Other Lipid Mediat. 2014;109-111:14-22.
6. Samad TA, Moore KA, Sapirstein A, Billet S, Allchorne A, Poole S, Bonventre $\mathrm{JV}$, Woolf CJ. Interleukin-1 beta-mediated induction of cox-2 in the CNS contributes to inflammatory pain hypersensitivity. Nature. 2001;410:471-5.

7. Beiche F, Scheuerer S, Brune K, Geisslinger G, Goppelt-Struebe M. Upregulation of cyclooxygenase-2 mRNA in the rat spinal cord following peripheral inflammation. FEBS Lett. 1996;390:165-9.

8. Ebersberger A, Grubb BD, Willingale HL, Gardiner NJ, Nebe J, Schaible HG. The intraspinal release of prostaglandin E2 in a model of acute arthritis is accompanied by an up-regulation of cyclo-oxygenase- 2 in the spinal cord. Neuroscience. 1999;93:775-81.

9. Tegeder I, Niederberger E, Vetter G, Brautigam L, Geisslinger G. Effects of selective COX-1 and -2 inhibition on formalin-evoked nociceptive behaviour and prostaglandin E(2) release in the spinal cord. J Neurochem. 2001;79:777-86.

10. Yaksh TL, Dirig DM, Conway CM, Svensson C, Luo ZD, Isakson PC. The acute antihyperalgesic action of nonsteroidal, anti-inflammatory drugs and release of spinal prostaglandin E2 is mediated by the inhibition of constitutive spinal cyclooxygenase-2 (COX-2) but not COX-1. J Neurosci. 2001;21:5847-53.

11. Hefferan MP, Carter P, Haley M, Loomis CW. Spinal nerve injury activates prostaglandin synthesis in the spinal cord that contributes to early maintenance of tactile allodynia. Pain. 2003;101:139-47.

12. Zhu X, Eisenach JC. Cyclooxygenase-1 in the spinal cord is altered after peripheral nerve injury. Anesthesiology. 2003;99:1175-9.

13. Grill M, Peskar BA, Schuligoi R, Amann R. Systemic inflammation induces COX-2 mediated prostaglandin D2 biosynthesis in mice spinal cord. Neuropharmacology. 2006;50:165-73.

14. Willingale HL, Gardiner NJ, McLymont N, Giblett S, Grubb BD. Prostanoids synthesized by cyclo-oxygenase isoforms in rat spinal cord and their contribution to the development of neuronal hyperexcitability. $\mathrm{Br} J$ Pharmacol. 1997;122:1593-604.

15. Ballou LR, Botting RM, Goorha S, Zhang J, Vane JR. Nociception in cyclooxygenase isozyme-deficient mice. Proc Natl Acad Sci U S A. 2000;97:10272-6.

16. Chopra B, Giblett S, Little JG, Donaldson LF, Tate S, Evans RJ, Grubb BD. Cyclooxygenase-1 is a marker for a subpopulation of putative nociceptive neurons in rat dorsal root ganglia. Eur J Neurosci. 2000;12:911-20.

17. Dou W, Jiao Y, Goorha S, Raghow R, Ballou LR. Nociception and the differential expression of cyclooxygenase-1 (COX-1), the COX-1 variant retaining intron-1 (COX-1v), and COX-2 in mouse dorsal root ganglia (DRG). Prostaglandins Other Lipid Mediat. 2004;74:29-43.

18. Grill M, Heinemann A, Hoefler G, Peskar BA, Schuligoi R. Effect of endotoxin treatment on the expression and localization of spinal cyclooxygenase, prostaglandin synthases, and PGD2 receptors. J Neurochem. 2008;104:1345-57.

19. Pham-Marcou TA, Beloeil H, Sun X, Gentili M, Yaici D, Benoit G, Benhamou $D$, Mazoit JX. Antinociceptive effect of resveratrol in carrageenan-evoked hyperalgesia in rats: prolonged effect related to COX-2 expression impairment. Pain. 2008;140:274-83.

20. Amaya F, Samad TA, Barrett L, Broom DC, Woolf CJ. Periganglionic inflammation elicits a distally radiating pain hypersensitivity by promoting COX-2 induction in the dorsal root ganglion. Pain. 2009;142:59-67.

21. Araldi D, Ferrari LF, Lotufo CM, Vieira AS, Athie MC, Figueiredo JG, Duarte $\mathrm{DB}$, Tambeli $\mathrm{CH}$, Ferreira SH, Parada CA. Peripheral inflammatory hyperalgesia depends on the COX increase in the dorsal root ganglion. Proc Natl Acad Sci U S A. 2013;110:3603-8.

22. Le Pichon CE, Chesler AT. The functional and anatomical dissection of somatosensory subpopulations using mouse genetics. Front Neuroanat. 2014;8:21.

23. Jang Y, Cho PS, Yang YD, Hwang SW. Nociceptive roles of TRPM2 Ion Channel in pathologic pain. Mol Neurobiol. 2018;55:6589-600.

24. Inoue A, Iwasa M, Nishikura Y, Ogawa S, Nakasuka A, Nakata Y. The longterm exposure of rat cultured dorsal root ganglion cells to bradykinin induced the release of prostaglandin $\mathrm{E} 2$ by the activation of cyclooxygenase-2. Neurosci Lett. 2006;401:242-7.

25. Cheng L, Jia H, Lohr M, Bagherzadeh A, Holmes DI, Selwood D, Zachary I. Antichemorepulsive effects of vascular endothelial growth factor and placental growth factor-2 in dorsal root ganglion neurons are mediated via neuropilin-1 and cyclooxygenase-derived prostanoid production. J Biol Chem. 2004;279:30654-61.

26. Vellani V, Franchi S, Prandini M, Moretti S, Castelli M, Giacomoni C, Sacerdote P. Effects of NSAIDs and paracetamol (acetaminophen) on protein kinase C epsilon translocation and on substance P synthesis and release in cultured sensory neurons. J Pain Res. 2013;6:111-20.

27. Ma K, Zhou QH, Chen J, Du DP, Ji Y, Jiang W. TTX-R Na+ current-reduction by celecoxib correlates with changes in PGE(2) and CGRP within rat DRG neurons during acute incisional pain. Brain Res. 2008;1209:57-64. 
28. Wang Y, Zhang X, Guo QL, Zou WY, Huang CS, Yan JQ. Cyclooxygenase inhibitors suppress the expression of P2X(3) receptors in the DRG and attenuate hyperalgesia following chronic constriction injury in rats. Neurosci Lett. 2010;478:77-81.

29. Syriatowicz JP, Hu D, Walker JS, Tracey DJ. Hyperalgesia due to nerve injury: role of prostaglandins. Neuroscience. 1999;94:587-94.

30. Goncalves MB, Williams EJ, Yip P, Yanez-Munoz RJ, Williams G, Doherty P. The COX-2 inhibitors, meloxicam and nimesulide, suppress neurogenesis in the adult mouse brain. Br J Pharmacol. 2010;159:1118-25.

31. Fehrenbacher JC, Burkey TH, Nicol GD, Vasko MR. Tumor necrosis factor alpha and interleukin-1 beta stimulate the expression of cyclooxygenase ॥ but do not alter prostaglandin E2 receptor mRNA levels in cultured dorsal root ganglia cells. Pain. 2005;113:113-22.

32. Gould HJ 3rd, England JD, Soignier RD, Nolan P, Minor LD, Liu ZP, Levinson SR, Paul D. Ibuprofen blocks changes in Na $\vee 1.7$ and 1.8 sodium channels associated with complete Freund's adjuvant-induced inflammation in rat. J Pain. 2004;5:270-80.

33. Inoue A, Ikoma K, Morioka N, Kumagai K, Hashimoto T, Hide I, Nakata Y. Interleukin-1 beta induces substance $P$ release from primary afferent neurons through the cyclooxygenase-2 system. J Neurochem. 1999;73:2206-13.

34. Morioka N, Inoue A, Hanada T, Kumagai K, Takeda K, Ikoma K, Hide I, Tamura Y, Shiomi H, Dohi T, Nakata Y. Nitric oxide synergistically potentiates interleukin-1 beta-induced increase of cyclooxygenase-2 mRNA levels, resulting in the facilitation of substance $P$ release from primary afferent neurons: involvement of CGMP-independent mechanisms. Neuropharmacology. 2002;43:868-76.

35. Cruz Duarte P, St-Jacques B, Ma W. Prostaglandin E2 contributes to the synthesis of brain-derived neurotrophic factor in primary sensory neuron in ganglion explant cultures and in a neuropathic pain model. Exp Neurol. 2012;234:466-81.

36. Junger $\mathrm{H}$, Sorkin LS. C-nociceptor sensitization by isoprostanes is cyclooxygenase dependent. Brain Res. 2000;867:255-8.

37. Nicol GD, Lopshire JC, Pafford CM. Tumor necrosis factor enhances the capsaicin sensitivity of rat sensory neurons. J Neurosci. 1997;17:975-82.

38. Jang IJ, Davies AJ, Akimoto N, Back SK, Lee PR, Na HS, Furue H, Jung SJ, Kim $\mathrm{YH}$, Oh SB. Acute inflammation reveals GABAA receptor-mediated nociception in mouse dorsal root ganglion neurons via PGE2 receptor 4 signaling. Physiol Rep. 2017:5:e13178.

39. Sun W, Yang F, Wang Y, Fu H, Yang Y, Li CL, Wang XL, Lin Q, Chen J. Contribution of large-sized primary sensory neuronal sensitization to mechanical allodynia by upregulation of hyperpolarization-activated cyclic nucleotide gated channels via cyclooxygenase 1 cascade. Neuropharmacology. 2017;113:217-30.

40. Taiwo Y, Heller P, Levine J. Characterization of distinct phospholipases mediating bradykinin and noradrenaline hyperalgesia. Neuroscience. 1990;39:523-31.

41. Ferreira S, Lorenzetti B, Poole S. Bradykinin initiates cytokine-mediated inflammatory hyperalgesia. Br J Pharmacol. 1993;110:1227-31.

42. Supowit SC, Zhao H, Katki KA, Gupta P, Dipette DJ. Bradykinin and prostaglandin $\mathrm{E}(1)$ regulate calcitonin gene-related peptide expression in cultured rat sensory neurons. Regul Pept. 2011;167:105-11.

43. Jenkins DW, Sellers LA, Feniuk W, Humphrey PP. Characterization of bradykinin-induced prostaglandin E2 release from cultured rat trigeminal ganglion neurones. Eur J Pharmacol. 2003;469:29-36.

44. Xanthos DN, Sandkuhler J. Neurogenic neuroinflammation: inflammatory CNS reactions in response to neuronal activity. Nat Rev Neurosci. 2014;15:43-53.

45. Ma W, Chabot JG, Vercauteren F, Quirion R. Injured nerve-derived COX2/ PGE2 contributes to the maintenance of neuropathic pain in aged rats. Neurobiol Aging. 2010;31:1227-37.

46. Murakami M, Naraba H, Tanioka T, Semmyo N, Nakatani $Y$, Kojima F, Ikeda T, Fueki M, Ueno A, Oh S, Kudo I. Regulation of prostaglandin E2 biosynthesis by inducible membrane-associated prostaglandin E2 synthase that acts in concert with cyclooxygenase-2. J Biol Chem. 2000; 275:32783-92.

47. Urade $Y$, Eguchi N. Lipocalin-type and hematopoietic prostaglandin D synthases as a novel example of functional convergence. Prostaglandins Other Lipid Mediat. 2002;68-69:375-82.

48. Ujihara M, Urade Y, Eguchi N, Hayashi H, Ikai K, Hayaishi O. Prostaglandin D2 formation and characterization of its synthetases in various tissues of adult rats. Arch Biochem Biophys. 1988;260:521-31.

49. Pinho-Ribeiro FA, Verri WA Jr, Chiu IM. Nociceptor sensory neuron-immune interactions in pain and inflammation. Trends Immunol. 2017;38:5-19.

50. Cunha TM, Verri WA Jr, Schivo IR, Napimoga MH, Parada CA, Poole S, Teixeira MM, Ferreira SH, Cunha FQ. Crucial role of neutrophils in the development of mechanical inflammatory hypernociception. J Leukoc Biol. 2008;83:824-32.
51. Ma W, Quirion R. Up-regulation of interleukin- 6 induced by prostaglandin $E$ from invading macrophages following nerve injury: an in vivo and in vitro study. J Neurochem. 2005;93:664-73.

52. Chopra S, Giovanelli P, Alvarado-Vazquez PA, Alonso S, Song M, Sandoval TA, Chae CS, Tan C, Fonseca MM, Gutierrez S, et al. IRE1alpha-XBP1 signaling in leukocytes controls prostaglandin biosynthesis and pain. Science. 2019; 365:eaau6499.

53. Vesin MF, Droz B. Biosynthesis of prostaglandins D2 and E2 in chick dorsal root ganglion during development. J Neurochem. 1991;57:161-6.

54. Vesin MF, Barakat-Walter I, Droz B. Preferential synthesis of prostaglandin D2 by neurons and prostaglandin E2 by fibroblasts and nonneuronal cells in chick dorsal root ganglia. J Neurochem. 1991;57:167-74.

55. Vesin MF, Urade Y, Hayaishi O, Droz B. Neuronal and glial prostaglandin D synthase isozymes in chick dorsal root ganglia: a light and electron microscopic immunocytochemical study. J Neurosci. 1995;15:470-6.

56. Vesin MF, Droz B. Immunodetection of prostaglandin D synthase: conditions of localization in a defined subclass of primary sensory neurons. J Histochem Cytochem. 1995;43.681-7.

57. Schuligoi R, Ulcar R, Peskar BA, Amann R. Effect of endotoxin treatment on the expression of cyclooxygenase-2 and prostaglandin synthases in spinal cord, dorsal root ganglia, and skin of rats. Neuroscience. 2003;1 16:1043-52.

58. Kunori S, Matsumura S, Okuda-Ashitaka E, Katano T, Audoly LP, Urade Y, Ito S. A novel role of prostaglandin E2 in neuropathic pain: blockade of microglial migration in the spinal cord. Glia. 2011;59:208-18.

59. Trimarco A, Forese MG, Alfieri V, Lucente A, Brambilla P, Dina G, Pieragostino D, Sacchetta P, Urade Y, Boizet-Bonhoure B, et al. Prostaglandin D2 synthase/ GPR44: a signaling axis in PNS myelination. Nat Neurosci. 2014;17:1682-92.

60. Schafers M, Marziniak M, Sorkin LS, Yaksh TL, Sommer C. Cyclooxygenase inhibition in nerve-injury- and TNF-induced hyperalgesia in the rat. Exp Neurol. 2004;185:160-8.

61. Souza GR, Talbot J, Lotufo CM, Cunha FQ, Cunha TM, Ferreira SH. Fractalkine mediates inflammatory pain through activation of satellite glial cells. Proc Natl Acad Sci U S A. 2013;110:11193-8.

62. Zeisel A, Hochgerner $H$, Lonnerberg $P$, Johnsson A, Memic F, van der Zwan J. Haring M, Braun E, Borm LE, La Manno G, et al. Molecular architecture of the mouse nervous system. Cell. 2018;174:999-1014 e1022.

63. Austin PJ, Moalem-Taylor G. The neuro-immune balance in neuropathic pain: involvement of inflammatory immune cells, immune-like glial cells and cytokines. J Neuroimmunol. 2010:229:26-50.

64. Ghilardi JR, Svensson Cl, Rogers SD, Yaksh TL, Mantyh PW. Constitutive spinal cyclooxygenase-2 participates in the initiation of tissue injury-induced hyperalgesia. J Neurosci. 2004;24:2727-32.

65. Svensson $\mathrm{Cl}$, Hua XY, Protter AA, Powell HC, Yaksh TL. Spinal p38 MAP kinase is necessary for NMDA-induced spinal PGE(2) release and thermal hyperalgesia. Neuroreport. 2003;14:1153-7.

66. Dirig DM, Yaksh TL. Spinal synthesis and release of prostanoids after peripheral injury and inflammation. Adv Exp Med Biol. 1999;469:401-8.

67. Muja N, DeVries GH. Prostaglandin E(2) and 6-keto-prostaglandin F(1alpha) production is elevated following traumatic injury to sciatic nerve. Glia. 2004;46:116-29.

68. Capuano A, De Corato A, Lisi L, Tringali G, Navarra P, Dello Russo C. Proinflammatory-activated trigeminal satellite cells promote neuronal sensitization: relevance for migraine pathology. Mol Pain. 2009;5:43.

69. Trebino CE, Stock JL, Gibbons CP, Naiman BM, Wachtmann TS, Umland JP, Pandher K, Lapointe JM, Saha S, Roach ML, et al. Impaired inflammatory and pain responses in mice lacking an inducible prostaglandin E synthase. Proc Natl Acad Sci U S A. 2003;100:9044-9.

70. Kamei D, Yamakawa K, Takegoshi Y, Mikami-Nakanishi M, Nakatani Y, Oh-Ishi S, Yasui H, Azuma Y, Hirasawa N, Ohuchi K, et al. Reduced pain hypersensitivity and inflammation in mice lacking microsomal prostaglandin e synthase-1. J Biol Chem. 2004;279:33684-95.

71. Brenneis C, Coste O, Schmidt R, Angioni C, Popp L, Nusing RM, Becker W, Scholich K, Geisslinger G. Consequences of altered eicosanoid patterns for nociceptive processing in MPGES-1-deficient mice. J Cell Mol Med. 2008;12:639-48.

72. Mabuchi T, Kojima H, Abe T, Takagi K, Sakurai M, Ohmiya Y, Uematsu S, Akira S, Watanabe K, Ito S. Membrane-associated prostaglandin E synthase-1 is required for neuropathic pain. Neuroreport. 2004;15:1395-8.

73. Scholich K, Geisslinger G. Is mPGES-1 a promising target for pain therapy? Trends Pharmacol Sci. 2006;27:399-401.

74. Eguchi N, Minami T, Shirafuji N, Kanaoka Y, Tanaka T, Nagata A, Yoshida N, Urade Y, Ito S, Hayaishi O. Lack of tactile pain (allodynia) in lipocalin-type prostaglandin D synthase-deficient mice. Proc Natl Acad Sci U S A. 1999;96:726-30. 
75. Kawahara K, Hohjoh H, Inazumi T, Tsuchiya S, Sugimoto Y. Prostaglandin E2induced inflammation: relevance of prostaglandin E receptors. Biochim Biophys Acta. 1851;2015:414-21.

76. Jabbour HN, Sales KJ. Prostaglandin receptor signalling and function in human endometrial pathology. Trends Endocrinol Metab. 2004;15:398-404.

77. Oida H, Namba T, Sugimoto Y, Ushikubi F, Ohishi H, Ichikawa A, Narumiya S In situ hybridization studies of prostacyclin receptor mRNA expression in various mouse organs. Br J Pharmacol. 1995;116:2828-37.

78. Southall MD, Vasko MR. Prostaglandin receptor subtypes, EP3C and EP4, mediate the prostaglandin E2-induced CAMP production and sensitization of sensory neurons. J Biol Chem. 2001;276:16083-91.

79. Natura G, Bar KJ, Eitner A, Boettger MK, Richter F, Hensellek S, Ebersberger A, Leuchtweis J, Maruyama T, Hofmann GO, et al. Neuronal prostaglandin E2 receptor subtype EP3 mediates antinociception during inflammation. Proc Natl Acad Sci U S A. 2013;110:13648-53.

80. Patwardhan AM, Vela J, Farugia J, Vela K, Hargreaves KM. Trigeminal nociceptors express prostaglandin receptors. J Dent Res. 2008;87:262-6.

81. Kras JV, Dong L, Winkelstein BA. The prostaglandin E2 receptor, EP2, is upregulated in the dorsal root ganglion after painful cervical facet joint injury in the rat. Spine (Phila Pa 1976). 2013;38:217-22.

82. Durrenberger PF, Facer P, Casula MA, Yiangou Y, Gray RA, Chessell IP, Day NC, Collins SD, Bingham S, Wilson AW, et al. Prostanoid receptor EP1 and cox-2 in injured human nerves and a rat model of nerve injury: a timecourse study. BMC Neurol. 2006;6:1.

83. Greaves E, Horne AW, Jerina H, Mikolajczak M, Hilferty L, Mitchell R, Fleetwood-Walker SM, Saunders PT. EP2 receptor antagonism reduces peripheral and central hyperalgesia in a preclinical mouse model of endometriosis. Sci Rep. 2017;7:44169.

84. Sekiguchi M, Otoshi K, Kikuchi S, Konno S. Analgesic effects of prostaglandin E2 receptor subtype EP1 receptor antagonist: experimental study of application of nucleus pulposus. Spine (Phila Pa 1976). 2011;36:1829-34.

85. Borgland SL, Connor M, Ryan RM, Ball HJ, Christie MJ. Prostaglandin E(2) inhibits calcium current in two sub-populations of acutely isolated mouse trigeminal sensory neurons. J Physiol. 2002;539:433-44.

86. Bar KJ, Natura G, Telleria-Diaz A, Teschner P, Vogel R, Vasquez E, Schaible HG, Ebersberger A. Changes in the effect of spinal prostaglandin E2 during inflammation: prostaglandin E (EP1-EP4) receptors in spinal nociceptive processing of input from the normal or inflamed knee joint. J Neurosci. 2004;24:642-51.

87. Treutlein EM, Kern K, Weigert A, Tarighi N, Schuh CD, Nusing RM, Schreiber $Y$, Ferreiros N, Brune B, Geisslinger G, et al. The prostaglandin E2 receptor EP3 controls CC-chemokine ligand 2-mediated neuropathic pain induced by mechanical nerve damage. J Biol Chem. 2018;293:9685-95.

88. Nakayama Y, Omote K, Kawamata T, Namiki A. Role of prostaglandin receptor subtype EP1 in prostaglandin E2-induced nociceptive transmission in the rat spinal dorsal horn. Brain Res. 2004;1010:62-8.

89. Gold MS, Levine JD, Correa AM. Modulation of TTX-R INa by PKC and PKA and their role in PGE2-induced sensitization of rat sensory neurons in vitro. J Neurosci. 1998;18:10345-55.

90. Sachs D, Villarreal C, Cunha F, Parada C, Ferreira S. The role of PKA and PKCepsilon pathways in prostaglandin E2-mediated hypernociception. Br J Pharmacol. 2009;156:826-34.

91. Waters MJ, Brooks AJ. JAK2 activation by growth hormone and other cytokines. Biochem J. 2015;466:1-11.

92. Tamura S, Morikawa Y, Senba E. Up-regulated phosphorylation of signal transducer and activator of transcription 3 and cyclic AMP-responsive element binding protein by peripheral inflammation in primary afferent neurons possibly through oncostatin M receptor. Neuroscience. 2005;133:797-806.

93. Dominguez E, Rivat C, Pommier B, Mauborgne A, Pohl M. JAK/STAT3 pathway is activated in spinal cord microglia after peripheral nerve injury and contributes to neuropathic pain development in rat. J Neurochem. 2008;107:50-60.

94. Vieira AS, Araldi D, Dias EV, do Prado FC, Tambeli CH, Parada CA. Janus kinase 2 activation participates in prostaglandin E2-induced hyperalgesia. Life Sci. 2016;166:8-12.

95. Aley $\mathrm{KO}, \mathrm{McC}$ arter $\mathrm{G}$, Levine JD. Nitric oxide signaling in pain and nociceptor sensitization in the rat. J Neurosci. 1998;18:7008-14.

96. St-Jacques B, Ma W. Role of prostaglandin E2 in the synthesis of the proinflammatory cytokine interleukin-6 in primary sensory neurons: an in vivo and in vitro study. J Neurochem. 2011;118:841-54.

97. Tse KH, Chow KB, Leung WK, Wong YH, Wise H. Lipopolysaccharide differentially modulates expression of cytokines and cyclooxygenases in dorsal root ganglion cells via toll-like receptor-4 dependent pathways. Neuroscience. 2014;267:241-51

98. Tse KH, Chow KB, Leung WK, Wong YH, Wise H. Primary sensory neurons regulate toll-like receptor-4-dependent activity of glial cells in dorsal root ganglia. Neuroscience. 2014;279:10-22.

99. Tse $\mathrm{KH}$, Chow KB, Wise H. PGE2 released by primary sensory neurons modulates toll-like receptor 4 activities through an EP4 receptor-dependent process. J Neuroimmunol. 2016;293:8-16.

100. Baba H, Kohno T, Moore KA, Woolf CJ. Direct activation of rat spinal dorsal horn neurons by prostaglandin E2. J Neurosci. 2001;21:1750-6.

101. Ahmadi S, Lippross S, Neuhuber WL, Zeilhofer HU. PGE(2) selectively blocks inhibitory glycinergic neurotransmission onto rat superficial dorsal horn neurons. Nat Neurosci. 2002:5:34-40.

102. Harvey RJ, Depner UB, Wassle H, Ahmadi S, Heindl C, Reinold H, Smart TG, Harvey K, Schutz B, Abo-Salem OM, et al. GlyR alpha3: an essential target for spinal PGE2-mediated inflammatory pain sensitization. Science. 2004;304:884-7

103. Reinold H, Ahmadi S, Depner UB, Layh B, Heindl C, Hamza M, Pahl A, Brune K, Narumiya S, Muller U, Zeilhofer HU. Spinal inflammatory hyperalgesia is mediated by prostaglandin E receptors of the EP2 subtype. J Clin Invest. 2005;115:673-9.

104. Hosl K, Reinold H, Harvey RJ, Muller U, Narumiya S, Zeilhofer HU. Spinal prostaglandin E receptors of the EP2 subtype and the glycine receptor alpha3 subunit, which mediate central inflammatory hyperalgesia, do not contribute to pain after peripheral nerve injury or formalin injection. Pain. 2006;126:46-53.

105. Li J, Serafin E, Baccei ML. Prostaglandin Signaling governs spike timingdependent plasticity at sensory synapses onto mouse spinal projection neurons. J Neurosci. 2018;38:6628-39.

106. Smith JA, Amagasu SM, Eglen RM, Hunter JC, Bley KR. Characterization of prostanoid receptor-evoked responses in rat sensory neurones. $\mathrm{Br} \mathrm{J}$ Pharmacol. 1998;124:513-23.

107. Rowlands DK, Kao C, Wise H. Regulation of prostacyclin and prostaglandin $\mathrm{E}(2)$ receptor mediated responses in adult rat dorsal root ganglion cells, in vitro. Br J Pharmacol. 2001;133:13-22.

108. Wise H. Lack of interaction between prostaglandin E2 receptor subtypes in regulating adenylyl cyclase activity in cultured rat dorsal root ganglion cells. Eur J Pharmacol. 2006;535:69-77.

109. Lin CR, Amaya F, Barrett L, Wang H, Takada J, Samad TA, Woolf CJ. Prostaglandin E2 receptor EP4 contributes to inflammatory pain hypersensitivity. J Pharmacol Exp Ther. 2006;319:1096-103.

110. St-Jacques B, Ma W. Prostaglandin E2/EP4 signalling facilitates EP4 receptor externalization in primary sensory neurons in vitro and in vivo. Pain. 2013; 154:313-23

111. St-Jacques $B$, Ma W. Preferred recycling pathway by internalized PGE2 EP4 receptor following agonist stimulation in cultured dorsal root ganglion neurons contributes to enhanced EP4 receptor sensitivity. Neuroscience. 2016;326:56-68

112. St-Jacques B, Ma W. Peripheral prostaglandin E2 prolongs the sensitization of nociceptive dorsal root ganglion neurons possibly by facilitating the synthesis and anterograde axonal trafficking of EP4 receptors. Exp Neurol. 2014;261:354-66.

113. Ng KY, Wong $\mathrm{YH}$, Wise $\mathrm{H}$. Glial cells isolated from dorsal root ganglia express prostaglandin $\mathrm{E}(2)(\mathrm{EP}(4))$ and prostacyclin (IP) receptors. Eur J Pharmacol. 2011;661:42-8.

114. Jenkins DW, Feniuk W, Humphrey PP. Characterization of the prostanoid receptor types involved in mediating calcitonin gene-related peptide release from cultured rat trigeminal neurones. Br J Pharmacol. 2001;134:1296-302.

115. Ebersberger A, Natura G, Eitner A, Halbhuber KJ, Rost R, Schaible HG. Effects of prostaglandin D2 on tetrodotoxin-resistant $\mathrm{Na}$ + currents in DRG neurons of adult rat. Pain. 2011;152:1114-26.

116. Sekeroglu A, Jacobsen JM, Jansen-Olesen I, Gupta S, Sheykhzade M, Olesen J, Bhatt DK. Effect of PGD2 on middle meningeal artery and mRNA expression profile of L-PGD2 synthase and DP receptors in trigeminovascular system and other pain processing structures in rat brain. Pharmacol Rep. 2017:69:50-6.

117. Isensee J, Wenzel C, Buschow R, Weissmann R, Kuss AW, Hucho T. Subgroup-elimination transcriptomics identifies signaling proteins that define subclasses of TRPV1-positive neurons and a novel paracrine circuit. PLoS One. 2014:9:e115731.

118. Nagira Y, Goto K, Tanaka H, Aoki M, Furue S, Inagaki N, Tomita Y, Shichijo M. Prostaglandin D2 modulates neuronal excitation of the trigeminal ganglion to augment allergic rhinitis in Guinea pigs. J Pharmacol Exp Ther. 2016;357:273-80. 
119. Telleria-Diaz A, Ebersberger A, Vasquez E, Schache F, Kahlenbach J, Schaible HG. Different effects of spinally applied prostaglandin D2 on responses of dorsal horn neurons with knee input in normal rats and in rats with acute knee inflammation. Neuroscience. 2008;156:184-92.

120. Coleridge HM, Coleridge JC, Ginzel KH, Baker DG, Banzett RB, Morrison MA. Stimulation of 'irritant' receptors and afferent C-fibres in the lungs by prostaglandins. Nature. 1976;264:451-3.

121. Fowler JC, Greene R, Weinreich D. Two calcium-sensitive spike after-hyperpolarizations in visceral sensory neurones of the rabbit. J Physiol. 1985;365:59-75.

122. Weinreich D, Wonderlin WF. Inhibition of calcium-dependent spike afterhyperpolarization increases excitability of rabbit visceral sensory neurones. J Physiol. 1987;394:415-27.

123. Fowler JC, Wonderlin WF, Weinreich D. Prostaglandins block a Ca2+-dependent slow spike afterhyperpolarization independent of effects on Ca2+ influx in visceral afferent neurons. Brain Res. 1985;345:345-9.

124. Gold MS, Shuster MJ, Levine JD. Role of a Ca(2+)-dependent slow afterhyperpolarization in prostaglandin E2-induced sensitization of cultured rat sensory neurons. Neurosci Lett. 1996;205:161-4.

125. England S, Bevan S, Docherty RJ. PGE2 modulates the tetrodotoxin-resistant sodium current in neonatal rat dorsal root ganglion neurones via the cyclic AMP-protein kinase a cascade. J Physiol. 1996;495(Pt 2):429-40.

126. Fitzgerald EM, Okuse K, Wood JN, Dolphin AC, Moss SJ. CAMP-dependent phosphorylation of the tetrodotoxin-resistant voltage-dependent sodium channel SNS. J Physiol. 1999;516(Pt 2):433-46.

127. Baker MD, Chandra SY, Ding Y, Waxman SG, Wood JN. GTP-induced tetrodotoxin-resistant $\mathrm{Na}+$ current regulates excitability in mouse and rat small diameter sensory neurones. J Physiol. 2003;548:373-82.

128. Saab CY, Cummins TR, Waxman SG. GTP gamma S increases Nav1.8 current in small-diameter dorsal root ganglia neurons. Exp Brain Res. 2003;152:415-9.

129. Rush AM, Waxman SG. PGE2 increases the tetrodotoxin-resistant Nav1.9 sodium current in mouse DRG neurons via G-proteins. Brain Res. 2004;1023:264-71.

130. Gold MS. Sodium channels and pain therapy. Curr Opin Anaesthesiol. 2000;13:565-72.

131. Tripathi PK, Cardenas CG, Cardenas CA, Scroggs RS. Up-regulation of tetrodotoxin-sensitive sodium currents by prostaglandin $\mathrm{E}(2)$ in type-4 rat dorsal root ganglion cells. Neuroscience. 2011;185:14-26.

132. Khasar SG, Gold MS, Levine JD. A tetrodotoxin-resistant sodium current mediates inflammatory pain in the rat. Neurosci Lett. 1998;256:17-20.

133. Zhang P, Gan YH. Prostaglandin E2 Upregulated Trigeminal Ganglionic Sodium Channel 1.7 Involving Temporomandibular Joint Inflammatory Pain in Rats. Inflammation. 2017:40:1102-9.

134. Liu C, Li Q, Su Y, Bao L. Prostaglandin E2 promotes Na1.8 trafficking via its intracellular RRR motif through the protein kinase a pathway. Traffic. 2010;11:405-17.

135. Kerr BJ, Souslova V, McMahon SB, Wood JN. A role for the TTX-resistant sodium channel Nav 1.8 in NGF-induced hyperalgesia, but not neuropathic pain. Neuroreport. 2001;12:3077-80.

136. Sekiguchi F, Aoki Y, Nakagawa M, Kanaoka D, Nishimoto $Y$, Tsubota-Matsunami M, Yamanaka R, Yoshida S, Kawabata A. AKAP-dependent sensitization of Ca(v) 3.2 channels via the EP(4) receptor/CAMP pathway mediates PGE(2) -induced mechanical hyperalgesia. Br J Pharmacol. 2013;168:734-45.

137. Linley JE, Rose K, Ooi L, Gamper N. Understanding inflammatory pain: ion channels contributing to acute and chronic nociception. Pflugers Arch. 2010;459:657-69.

138. Hamilton SG, Wade A, McMahon SB. The effects of inflammation and inflammatory mediators on nociceptive behaviour induced by ATP analogues in the rat. Br J Pharmacol. 1999;126:326-32.

139. Wang C, Li GW, Huang LY. Prostaglandin E2 potentiation of P2X3 receptor mediated currents in dorsal root ganglion neurons. Mol Pain. 2007;3:22.

140. Wang C, Gu Y, Li GW, Huang LY. A critical role of the CAMP sensor Epac in switching protein kinase signalling in prostaglandin E2-induced potentiation of P2X3 receptor currents in inflamed rats. J Physiol. 2007;584:191-203.

141. Gu Y, Wang C, Li G, Huang LY. EXPRESS: F-actin links Epac-PKC signaling to purinergic $\mathrm{P} 2 \mathrm{X} 3$ receptors sensitization in dorsal root ganglia following inflammation. Mol Pain. 2016;12.

142. Prado FC, Araldi D, Vieira AS, Oliveira-Fusaro MC, Tambeli CH, Parada CA. Neuronal P2X3 receptor activation is essential to the hyperalgesia induced by prostaglandins and sympathomimetic amines released during inflammation. Neuropharmacology. 2013;67:252-8.

143. Kim BM, Lee SH, Shim WS, Oh U. Histamine-induced Ca(2+) influx via the PLA(2)/ lipoxygenase/TRPV1 pathway in rat sensory neurons. Neurosci Lett. 2004;361:159-62.

144. Shim WS, Tak MH, Lee MH, Kim M, Koo JY, Lee CH, Oh U. TRPV1 mediates histamine-induced itching via the activation of phospholipase A2 and 12lipoxygenase. J Neurosci. 2007;27:2331-7.
145. Hwang SW, Oh U. Current concepts of nociception: nociceptive molecular sensors in sensory neurons. Curr Opin Anaesthesiol. 2007;20:427-34.

146. Choi SI, Lim JY, Yoo S, Kim H, Hwang SW. Emerging role of spinal cord TRPV1 in pain exacerbation. Neural Plast. 2016;2016:5954890.

147. Kim YH, Back SK, Davies AJ, Jeong H, Jo HJ, Chung G, Na HS, Bae YC, Kim SJ, Kim JS, et al. TRPV1 in GABAergic interneurons mediates neuropathic mechanical allodynia and disinhibition of the nociceptive circuitry in the spinal cord. Neuron. 2012;74:640-7.

148. Ma W, Quirion R. Inflammatory mediators modulating the transient receptor potential vanilloid 1 receptor: therapeutic targets to treat inflammatory and neuropathic pain. Expert Opin Ther Targets. 2007;11:307-20.

149. Pitchford S, Levine JD. Prostaglandins sensitize nociceptors in cell culture. Neurosci Lett. 1991;132:105-8.

150. Lopshire JC, Nicol GD. The CAMP transduction cascade mediates the prostaglandin E2 enhancement of the capsaicin-elicited current in rat sensory neurons: whole-cell and single-channel studies. J Neurosci. 1998;18:6081-92.

151. Moriyama T, Higashi T, Togashi $K$, lida T, Segi E, Sugimoto $Y$, Tominaga T, Narumiya S, Tominaga M. Sensitization of TRPV1 by EP1 and IP reveals peripheral nociceptive mechanism of prostaglandins. Mol Pain. 2005;1:3.

152. Namba T, Oida H, Sugimoto $Y$, Kakizuka A, Negishi M, Ichikawa A, Narumiya S. CDNA cloning of a mouse prostacyclin receptor. Multiple signaling pathways and expression in thymic medulla. J Biol Chem. 1994;269:9986-92.

153. Schnizler K, Shutov LP, Van Kanegan MJ, Merrill MA, Nichols B, McKnight GS, Strack S, Hell JW, Usachev YM. Protein kinase a anchoring via AKAP150 is essential for TRPV1 modulation by forskolin and prostaglandin E2 in mouse sensory neurons. J Neurosci. 2008;28:4904-17.

154. Jeske NA, Diogenes A, Ruparel NB, Fehrenbacher JC, Henry M, Akopian AN, Hargreaves KM. A-kinase anchoring protein mediates TRPV1 thermal hyperalgesia through PKA phosphorylation of TRPV1. Pain. 2008;138:604-16.

155. Ma W, St-Jacques B, Rudakou U, Kim YN. Stimulating TRPV1 externalization and synthesis in dorsal root ganglion neurons contributes to PGE2 potentiation of TRPV1 activity and nociceptor sensitization. Eur J Pain. 2017;21:575-93.

156. Alessandri-Haber N, Yeh JJ, Boyd AE, Parada CA, Chen X, Reichling DB, Levine JD. Hypotonicity induces TRPV4-mediated nociception in rat. Neuron. 2003:39:497-511.

157. Alessandri-Haber N, Dina OA, Yeh JJ, Parada CA, Reichling DB, Levine JD. Transient receptor potential vanilloid 4 is essential in chemotherapyinduced neuropathic pain in the rat. J Neurosci. 2004;24:4444-52.

158. Alessandri-Haber N, Joseph E, Dina OA, Liedtke W, Levine JD. TRPV4 mediates pain-related behavior induced by mild hypertonic stimuli in the presence of inflammatory mediator. Pain. 2005;118:70-9.

159. Alessandri-Haber N, Dina OA, Joseph EK, Reichling D, Levine JD. A transient receptor potential vanilloid 4-dependent mechanism of hyperalgesia is engaged by concerted action of inflammatory mediators. J Neurosci. 2006;26:3864-74.

160. Chen X, Alessandri-Haber N, Levine JD. Marked attenuation of inflammatory mediator-induced C-fiber sensitization for mechanical and hypotonic stimuli in TRPV4-/- mice. Mol Pain. 2007:3:31.

161. Li CL, Li KC, Wu D, Chen Y, Luo H, Zhao JR, Wang SS, Sun MM, Lu YJ, Zhong $Y Q$, et al. Somatosensory neuron types identified by highcoverage single-cell RNA-sequencing and functional heterogeneity. Cell Res. 2016;26:83-102.

162. Yoo S, Choi SI, Lee S, Song J, Yang C, Bang S, Kim SU, Min KH, Hwang SW. Endogenous TRPV4 expression of a hybrid neuronal cell line N18D3 and its utilization to find a novel synthetic ligand. J Mol Neurosci. 2017;63:422-30.

163. Bang $S$, Yang TJ, Yoo S, Heo TH, Hwang SW. Inhibition of sensory neuronal TRPS contributes to anti-nociception by butamben. Neurosci Lett. 2012;506:297-302.

164. Bang S, Yoo S, Yang TJ, Cho H, Hwang SW. Nociceptive and pro-inflammatory effects of dimethylallyl pyrophosphate via TRPV4 activation. Br J Pharmacol. 2012;166:1433-43.

165. Bang S, Yoo S, Yang TJ, Cho H, Kim YG, Hwang SW. Resolvin D1 attenuates activation of sensory transient receptor potential channels leading to multiple anti-nociception. Br J Pharmacol. 2010;161:707-20.

166. Bandell M, Story GM, Hwang SW, Viswanath V, Eid SR, Petrus MJ, Earley TJ, Patapoutian A. Noxious cold ion channel TRPA1 is activated by pungent compounds and bradykinin. Neuron. 2004:41:849-57.

167. Kim S, Hwang SW. Emerging roles of TRPA1 in sensation of oxidative stress and its implications in defense and danger. Arch Pharm Res. 2013;36:783-91.

168. Dall'Acqua MC, Bonet IJ, Zampronio AR, Tambeli CH, Parada CA, Fischer L. The contribution of transient receptor potential ankyrin 1 (TRPA1) to the in vivo nociceptive effects of prostaglandin $E(2)$. Life Sci. 2014;105:7-13.

169. Cho H, Yang YD, Lee J, Lee B, Kim T, Jang Y, Back SK, Na HS, Harfe BD, Wang $F$, et al. The calcium-activated chloride channel anoctamin 1 acts as a heat sensor in nociceptive neurons. Nat Neurosci. 2012;15:1015-21. 
170. Morris ME, Di Costanzo GA, Fox S, Werman R. Depolarizing action of GABA (gamma-aminobutyric acid) on myelinated fibers of peripheral nerves. Brain Res. 1983;278:117-26.

171. Funk K, Woitecki A, Franjic-Wurtz C, Gensch T, Mohrlen F, Frings S. Modulation of chloride homeostasis by inflammatory mediators in dorsal root ganglion neurons. Mol Pain. 2008;4:32.

172. Usoskin D, Furlan A, Islam S, Abdo H, Lonnerberg P, Lou D, Hjerling-Leffler J, Haeggstrom J, Kharchenko O, Kharchenko PV, et al. Unbiased classification of sensory neuron types by large-scale single-cell RNA sequencing. Nat Neurosci. 2015;18:145-53.

173. Mao S, Garzon-Muvdi T, Di Fulvio M, Chen Y, Delpire E, Alvarez FJ, AlvarezLeefmans FJ. Molecular and functional expression of cation-chloride cotransporters in dorsal root ganglion neurons during postnatal maturation. J Neurophysiol. 2012;108:834-52.

174. Gilbert D, Franjic-Wurtz C, Funk K, Gensch T, Frings S, Mohrlen F. Differential maturation of chloride homeostasis in primary afferent neurons of the somatosensory system. Int J Dev Neurosci. 2007;25:479-89.

175. Morales-Aza BM, Chillingworth NL, Payne JA, Donaldson LF. Inflammation alters cation chloride cotransporter expression in sensory neurons. Neurobiol Dis. 2004;17:62-9.

176. Kanaka C, Ohno K, Okabe A, Kuriyama K, Itoh T, Fukuda A, Sato K. The differential expression patterns of messenger RNAs encoding $\mathrm{K}-\mathrm{Cl}$ cotransporters $(\mathrm{KCC} 1,2)$ and $\mathrm{Na}-\mathrm{K}-2 \mathrm{Cl}$ cotransporter (NKCC1) in the rat nervous system. Neuroscience. 2001;104:933-46.

177. Lu J, Karadsheh M, Delpire E. Developmental regulation of the neuronalspecific isoform of K-cl cotransporter KCC2 in postnatal rat brains. J Neurobiol. 1999;39:558-68.

178. Emery EC, Young GT, McNaughton PA. HCN2 ion channels: an emerging role as the pacemakers of pain. Trends Pharmacol Sci. 2012;33:456-63.

179. Chaplan SR, Guo HQ, Lee DH, Luo L, Liu C, Kuei C, Velumian AA, Butler MP, Brown SM, Dubin AE. Neuronal hyperpolarization-activated pacemaker channels drive neuropathic pain. J Neurosci. 2003;23:1169-78.

180. Tu H, Deng L, Sun Q, Yao L, Han JS, Wan Y. Hyperpolarization-activated, cyclic nucleotide-gated cation channels: roles in the differential electrophysiological properties of rat primary afferent neurons. J Neurosci Res. 2004;76:713-22.

181. Momin A, Cadiou H, Mason A, McNaughton PA. Role of the hyperpolarization-activated current Ih in somatosensory neurons. J Physiol. 2008;586:5911-29.

182. Cho HJ, Staikopoulos V, Furness JB, Jennings EA. Inflammation-induced increase in hyperpolarization-activated, cyclic nucleotide-gated channel protein in trigeminal ganglion neurons and the effect of buprenorphine. Neuroscience. 2009;162:453-61.

183. Ingram SL, Williams JT. Opioid inhibition of Ih via adenylyl cyclase. Neuron. 1994;13:179-86.

184. Ingram SL, Williams JT. Modulation of the hyperpolarization-activated current (Ih) by cyclic nucleotides in Guinea-pig primary afferent neurons. J Physiol. 1996:492(Pt 1):97-106.

185. Emery EC, Young GT, Berrocoso EM, Chen L, McNaughton PA. HCN2 ion channels play a central role in inflammatory and neuropathic pain. Science. 2011:333:1462-6.

186. Khan GM, Chen SR, Pan HL. Role of primary afferent nerves in allodynia caused by diabetic neuropathy in rats. Neuroscience. 2002;114:291-9.

187. Song Y, Li HM, Xie RG, Yue ZF, Song XJ, Hu SJ, Xing JL. Evoked bursting in injured Abeta dorsal root ganglion neurons: a mechanism underlying tactile allodynia. Pain. 2012;153:657-65.

188. Xiao WH, Bennett GJ. Persistent low-frequency spontaneous discharge in Afiber and C-fiber primary afferent neurons during an inflammatory pain condition. Anesthesiology. 2007;107:813-21.

189. Duan B, Cheng L, Bourane S, Britz O, Padilla C, Garcia-Campmany L, Krashes M, Knowlton W, Velasquez T, Ren X, et al. Identification of spinal circuits transmitting and gating mechanical pain. Cell. 2014;159:1417-32.

190. Wang H, Ehnert C, Brenner GJ, Woolf CJ. Bradykinin and peripheral sensitization. Biol Chem. 2006:387:11-4.

191. Vyklicky L, Knotkova-Urbancova H, Vitaskova Z, Vlachova V, Kress M, Reeh PW. Inflammatory mediators at acidic pH activate capsaicin receptors in cultured sensory neurons from newborn rats. J Neurophysiol. 1998;79:670-6.

192. Smith JA, Davis CL, Burgess GM. Prostaglandin E2-induced sensitization of bradykinin-evoked responses in rat dorsal root ganglion neurons is mediated by cAMP-dependent protein kinase a. Eur J Neurosci. 2000;12:3250-8.

193. Kasai M, Mizumura K. Effects of PGE(2) on neurons from rat dorsal root ganglia in intact and adjuvant-inflamed rats: role of NGF on PGE(2)-induced depolarization. Neurosci Res. 2001;41:345-53.
194. Gold MS, Gebhart GF. Nociceptor sensitization in pain pathogenesis. Nat Med. 2010;16:1248-57.

195. Taiwo YO, Levine JD. Characterization of the arachidonic acid metabolites mediating bradykinin and noradrenaline hyperalgesia. Brain Res. 1988;458:402-6.

196. Cunha TM, Verri WA, Fukada SY, Guerrero AT, Santodomingo-Garzón T, Poole S, Parada CA, Ferreira SH, Cunha FQ. TNF-a and IL-1 $\beta$ mediate inflammatory hypernociception in mice triggered by $B 1$ but not B 2 kinin receptor. Eur J Pharmacol. 2007;573:221-9.

197. Ferreira S, Lorenzetti B, Cunha F, Poole S. Bradykinin release of TNF-a plays a key role in the development of inflammatory hyperalgesia. Inflamm Res. 1993;38:C7-9.

198. Poole S, Lorenzetti B, Cunha J, Cunha F, Ferreira S. Bradykinin B1 and B2 receptors, tumour necrosis factor a and inflammatory hyperalgesia. $\mathrm{Br} \mathrm{J}$ Pharmacol. 1999:126:649-56.

199. Oshita K, Inoue A, Tang H-B, Nakata Y, Kawamoto M, Yuge O. CB1 cannabinoid receptor stimulation modulates transient receptor potential vanilloid receptor 1 activities in calcium influx and substance $P$ release in cultured rat dorsal root ganglion cells. J Pharmacol Sci. 2005;97:377-85.

200. Kopp UC, Cicha MZ, Nakamura K, Nusing RM, Smith LA, Hokfelt T. Activation of EP4 receptors contributes to prostaglandin E2-mediated stimulation of renal sensory nerves. Am J Physiol Renal Physiol. 2004;287:F1269-82.

201. Segond von Banchet G, Scholze A, Schaible HG. Prostaglandin E2 increases the expression of the neurokinin1 receptor in adult sensory neurones in culture: a novel role of prostaglandins. Br J Pharmacol. 2003;139:672-80.

202. Chiu IM, von Hehn CA, Woolf CJ. Neurogenic inflammation and the peripheral nervous system in host defense and immunopathology. Nat Neurosci. 2012;15:1063-7.

203. Anthony D, Jasinski DM. Postoperative pain management: morphine versus ketorolac. J Perianesth Nurs. 2002:17:30-42.

204. Tumati S, Roeske WR, Vanderah TW, Varga EV. Sustained morphine treatment augments prostaglandin E2-evoked calcitonin gene-related peptide release from primary sensory neurons in a PKA-dependent manner. Eur J Pharmacol. 2010;648:95-101.

205. Thompson SW, Bennett DL, Kerr BJ, Bradbury EJ, McMahon SB. Brain-derived neurotrophic factor is an endogenous modulator of nociceptive responses in the spinal cord. Proc Natl Acad Sci U S A. 1999;96:7714-8.

206. Zhou XF, Chie ET, Deng YS, Zhong JH, Xue Q, Rush RA, Xian CJ. Injured primary sensory neurons switch phenotype for brain-derived neurotrophic factor in the rat. Neuroscience. 1999;92:841-53.

207. Merighi A, Salio C, Ghirri A, Lossi L, Ferrini F, Betelli C, Bardoni R. BDNF as a pain modulator. Prog Neurobiol. 2008;85:297-317.

208. Wang X, Ratnam J, Zou B, England PM, Basbaum Al. TrkB signaling is required for both the induction and maintenance of tissue and nerve injury-induced persistent pain. J Neurosci. 2009;29:5508-15.

209. Quintao NL, Santos AR, Campos MM, Calixto JB. The role of neurotrophic factors in genesis and maintenance of mechanical hypernociception after brachial plexus avulsion in mice. Pain. 2008;136:125-33.

210. Choi SY, Choi BH, Suh BC, Chae HD, Kim JS, Shin MJ, Kang SS, Negishi M, Kim KT. Potentiation of PGE(2)-mediated CAMP production during neuronal differentiation of human neuroblastoma SK-N-BE(2) C cells. J Neurochem. 2001;79:303-10

211. Kim HS, Song M, Kim E, Ryu SH, Suh PG. Dexamethasone differentiates NG10815 cells through cyclooxygenase 1 induction. Exp Mol Med. 2003;35:203-10.

212. Mitani K, Sekiguchi F, Maeda T, Tanaka Y, Yoshida S, Kawabata A. The prostaglandin E2/EP4 receptor/cyclic AMP/T-type $\mathrm{Ca}(2+)$ channel pathway mediates neuritogenesis in sensory neuron-like ND7/23 cells. J Pharmacol Sci. 2016;130:177-80

213. Nango $H$, Kosuge $Y$, Miyagishi $H$, Sugawa $K$, Ito $Y$, Ishige $K$. Prostaglandin E2 facilitates neurite outgrowth in a motor neuron-like cell line, NSC-34. J Pharmacol Sci. 2017;135:64-71.

214. Hiruma H, Ichikawa T, Kobayashi H, Hoka S, Takenaka T, Kawakami T. Prostaglandin E(2) enhances axonal transport and neuritogenesis in cultured mouse dorsal root ganglion neurons. Neuroscience. 2000;100:885-91.

215. Sondell M, Lundborg G, Kanje M. Vascular endothelial growth factor has neurotrophic activity and stimulates axonal outgrowth, enhancing cell survival and Schwann cell proliferation in the peripheral nervous system. J Neurosci. 1999:19:5731-40.

216. Kelton JG, Blajchman MA. Prostaglandin 12 (prostacyclin). Can Med Assoc J. 1980;122:175-9.

217. Taiwo YO, Bjerknes LK, Goetzl EJ, Levine JD. Mediation of primary afferent peripheral hyperalgesia by the cAMP second messenger system. Neuroscience. 1989;32:577-80. 
218. Omana-Zapata I, Bley KR. A stable prostacyclin analog enhances ectopic activity in rat sensory neurons following neuropathic injury. Brain Res. 2001;904:85-92.

219. Nakae K, Hayashi F, Hayashi M, Yamamoto N, lino T, Yoshikawa S, Gupta J. Functional role of prostacyclin receptor in rat dorsal root ganglion neurons. Neurosci Lett. 2005;388:132-7.

220. Best LC, Martin TJ, Russell RG, Preston FE. Prostacyclin increases cyclic AMP levels and adenylate cyclase activity in platelets. Nature. 1977;267:850-2.

221. Murata T, Ushikubi F, Matsuoka T, Hirata M, Yamasaki A, Sugimoto Y, Ichikawa A, Aze Y, Tanaka T, Yoshida N, et al. Altered pain perception and inflammatory response in mice lacking prostacyclin receptor. Nature. 1997;388:678-82.

222. Nakae K, Saito K, lino T, Yamamoto N, Wakabayashi M, Yoshikawa S, Matsushima S, Miyashita H, Sugimoto H, Kiba A, Gupta J. A prostacyclin receptor antagonist inhibits the sensitized release of substance $P$ from rat sensory neurons. J Pharmacol Exp Ther. 2005;315:1136-42.

223. Andersson DA, Gentry C, Moss S, Bevan S. Transient receptor potential A1 is a sensory receptor for multiple products of oxidative stress. J Neurosci. 2008;28:2485-94.

224. Materazzi S, Nassini R, Andre E, Campi B, Amadesi S, Trevisani M, Bunnett NW, Patacchini R, Geppetti P. Cox-dependent fatty acid metabolites cause pain through activation of the irritant receptor TRPA1. Proc Natl Acad Sci U S A. 2008;105:12045-50.

225. Cruz-Orengo L, Dhaka A, Heuermann RJ, Young TJ, Montana MC, Cavanaugh EJ, Kim D, Story GM. Cutaneous nociception evoked by 15-delta PGJ2 via activation of ion channel TRPA1. Mol Pain. 2008;4:30.

226. Weng Y, Batista-Schepman PA, Barabas ME, Harris EQ, Dinsmore TB, Kossyreva EA, Foshage AM, Wang MH, Schwab MJ, Wang VM, et al. Prostaglandin metabolite induces inhibition of TRPA1 and channeldependent nociception. Mol Pain. 2012;8:75

227. Churi SB, Abdel-Aleem OS, Tumber KK, Scuderi-Porter H, Taylor BK. Intrathecal rosiglitazone acts at peroxisome proliferator-activated receptorgamma to rapidly inhibit neuropathic pain in rats. J Pain. 2008;9:639-49.

228. Napimoga MH, Souza GR, Cunha TM, Ferrari LF, Clemente-Napimoga JT, Parada CA, Verri WA Jr, Cunha FQ, Ferreira SH. 15d-prostaglandin J2 inhibits inflammatory hypernociception: involvement of peripheral opioid receptor. J Pharmacol Exp Ther. 2008;324:313-21.

229. Pena-dos-Santos DR, Severino FP, Pereira SA, Rodriques DB, Cunha FQ, Vieira SM, Napimoga MH, Clemente-Napimoga JT. Activation of peripheral kappa/delta opioid receptors mediates 15-deoxy-(Delta12,14)-prostaglandin J2 induced-antinociception in rat temporomandibular joint. Neuroscience. 2009;163:1211-9.

230. Hinman A, Chuang HH, Bautista DM, Julius D. TRP channel activation by reversible covalent modification. Proc Natl Acad Sci U S A. 2006;103:19564-8.

231. Bang S, Hwang SW. Polymodal ligand sensitivity of TRPA 1 and its modes of interactions. J Gen Physiol. 2009;133:257-62.

232. Macpherson L, Dubin AE, Evans MJ, Marr F, Schultz PG, Cravatt BF, Patapoutian A. Noxious compounds activate TRPA1 ion channels through covalent modification of cysteines. Nature. 2007;445:541-5.

233. Takahashi N, Mizuno Y, Kozai D, Yamamoto S, Kiyonaka S, Shibata T, Uchida K, Mori Y. Molecular characterization of TRPA1 channel activation by cysteine-reactive inflammatory mediators. Channels (Austin). 2008;2:287-98.

234. Taylor-Clark TE, Undem BJ, Macglashan DW Jr, Ghatta S, Carr MJ, McAlexander MA. Prostaglandin-induced activation of nociceptive neurons via direct interaction with transient receptor potential A1 (TRPA1). Mol Pharmacol. 2008;73:274-81.

235. Kapadia R, Yi JH, Vemuganti R. Mechanisms of anti-inflammatory and neuroprotective actions of PPAR-gamma agonists. Front Biosci. 2008;13:1813-26.

236. Ricote M, Li AC, Willson TM, Kelly CJ, Glass CK. The peroxisome proliferatoractivated receptor-gamma is a negative regulator of macrophage activation. Nature. 1998;391:79-82.

237. Mukherjee R, Jow L, Noonan D, McDonnell DP. Human and rat peroxisome proliferator activated receptors (PPARs) demonstrate similar tissue distribution but different responsiveness to PPAR activators. J Steroid Biochem Mol Biol. 1994;51:157-66.

238. Yagami T, Yamamoto $Y$, Koma H. Physiological and pathological roles of 15Deoxy-Delta(12,14)-prostaglandin J2 in the central nervous system and neurological diseases. Mol Neurobiol. 2018;55:2227-48.

239. Hamberg M, Svensson J, Samuelsson B. Thromboxanes: a new group of biologically active compounds derived from prostaglandin endoperoxides. Proc Natl Acad Sci U S A. 1975;72:2994-8.

240. Needleman P, Moncada S, Bunting S, Vane JR, Hamberg M, Samuelsson B. Identification of an enzyme in platelet microsomes which generates thromboxane A2 from prostaglandin endoperoxides. Nature. 1976;261:558-60.
241. Hirata M, Hayashi Y, Ushikubi F, Yokota Y, Kageyama R, Nakanishi S, Narumiya S. Cloning and expression of cDNA for a human thromboxane A2 receptor. Nature. 1991;349:617-20.

242. de Souza BF, Tricoci P. Novel anti-platelet agents: focus on thrombin receptor antagonists. J Cardiovasc Transl Res. 2013;6:415-24.

243. Ellinsworth DC, Shukla N, Fleming I, Jeremy JY. Interactions between thromboxane a(2), thromboxane/prostaglandin (TP) receptors, and endothelium-derived hyperpolarization. Cardiovasc Res. 2014;102:9-16.

244. Nakahata N. Thromboxane A2: physiology/pathophysiology, cellular signal transduction and pharmacology. Pharmacol Ther. 2008;118:18-35.

245. Karla W, Shams H, Orr JA, Scheid P. Effects of the thromboxane A2 mimetic, U46,619, on pulmonary vagal afferents in the cat. Respir Physiol. 1992;87:383-96.

246. Shams $H$, Scheid P. Effects of thromboxane on respiration and pulmonary circulation in the cat: role of vagus nerve. J Appl Physiol (1985). 1990;68:2042-6.

247. Aizawa $\mathrm{H}$, Hirose T. A possible mechanism of airway hyperresponsiveness induced by prostaglandin F2 alpha and thromboxane A2. Prostaglandins Leukot Essent Fatty Acids. 1988;33:185-9.

248. Pickar JG. The thromboxane A2 mimetic U-46619 inhibits somatomotor activity via a vagal reflex from the lung. Am J Phys. 1998:275:R706-12.

249. Carrithers JA, Liu F, Shirer HW, Orr JA. Mechanisms for the tachypneic response to the thromboxane $A 2$ mimetic $U-46,619$ in rabbits. Am J Phys. 1994;266:R321-7.

250. Wacker MJ, Tehrani RN, Smoot RL, Orr JA. Thromboxane a(2) mimetic evokes a bradycardia mediated by stimulation of cardiac vagal afferent nerves. Am J Physiol Heart Circ Physiol. 2002;282:H482-90.

251. Sun SY, Wang W, Schultz HD. Activation of cardiac afferents by arachidonic acid: relative contributions of metabolic pathways. Am J Physiol Heart Circ Physiol. 2001;281:H93-H104.

252. Kenagy J, VanCleave J, Pazdernik L, Orr JA. Stimulation of group III and IV afferent nerves from the hindlimb by thromboxane A2. Brain Res. 1997;744:175-8.

253. Mense S. Nociception from skeletal muscle in relation to clinical muscle pain. Pain. 1993:54:241-89.

254. Mitchell JH, Kaufman MP, Iwamoto GA. The exercise pressor reflex: its cardiovascular effects, afferent mechanisms, and central pathways. Annu Rev Physiol. 1983;45:229-42.

255. Fu LW, Guo ZL, Longhurst JC. Undiscovered role of endogenous thromboxane A2 in activation of cardiac sympathetic afferents during ischaemia. J Physiol. 2008:586:3287-300.

256. Wacker MJ, Tyburski JB, Ammar CP, Adams MC, Orr JA. Detection of thromboxane a(2) receptor $\mathrm{mRNA}$ in rabbit nodose ganglion neurons. Neurosci Lett. 2005;386:121-6.

257. Wacker MJ, Tevis O, Hanke J, Howard T, Gilbert W, Orr JA. Characterization of thromboxane a(2) receptor and TRPV1 mRNA expression in cultured sensory neurons. Neurosci Lett. 2012;515:12-7.

258. Andoh T, Nishikawa Y, Yamaguchi-Miyamoto T, Nojima H, Narumiya S, Kuraishi Y. Thromboxane A2 induces itch-associated responses through TP receptors in the skin in mice. J Invest Dermatol. 2007;127:2042-7.

259. Moore RA, Derry S, Aldington D, Cole P, Wiffen PJ. Adverse events associated with single dose oral analgesics for acute postoperative pain in adults - an overview of Cochrane reviews. Cochrane Database Syst Rev. 2015;10:CD011407.

260. Yezierski RP, Hansson P. Inflammatory and neuropathic pain from bench to bedside: what went wrong? J Pain. 2018;19:571-88.

261. Lim JY, Park CK, Hwang SW. Biological roles of Resolvins and related substances in the resolution of pain. Biomed Res Int. 2015;2015:830930.

262. Choi G, Hwang SW. Modulation of the activities of neuronal ion channels by fatty acid-derived pro-Resolvents. Front Physiol. 2016;7:523.

263. Jones RL, Giembycz MA, Woodward DF. Prostanoid receptor antagonists: development strategies and therapeutic applications. Br J Pharmacol. 2009; 158:104-45.

264. Hirata T, Narumiya S. Prostanoid receptors. Chem Rev. 2011;111:6209-30.

265. Ott D, Simm B, Pollatzek E, Gerstberger R, Rummel C, Roth J. Prostaglandin D2 modulates calcium signals induced by prostaglandin E2 in neurons of rat dorsal root ganglia. Neurosci Lett. 2015;597:159-63.

266. Popp L, Haussler A, Olliges A, Nusing R, Narumiya S, Geisslinger G, Tegeder I. Comparison of nociceptive behavior in prostaglandin E, F, D, prostacyclin and thromboxane receptor knockout mice. Eur J Pain. 2009;13:691-703.

267. Gibbs JL, Diogenes A, Hargreaves KM. Neuropeptide $Y$ modulates effects of bradykinin and prostaglandin E2 on trigeminal nociceptors via activation of the $Y 1$ and $Y 2$ receptors. Br J Pharmacol. 2007;150:72-9. 
268. Nicolson TA, Foster AF, Bevan S, Richards CD. Prostaglandin E2 sensitizes primary sensory neurons to histamine. Neuroscience. 2007;150:22-30.

269. Tai HH, Ensor CM, Tong M, Zhou H, Yan F. Prostaglandin catabolizing enzymes. Prostaglandins Other Lipid Mediat. 2002:68-69:483-93.

270. Zhang Y, Desai A, Yang SY, Bae KB, Antczak MI, Fink SP, Tiwari S, Willis JE, Williams NS, Dawson DM, et al. TISSUE REGENERATION. Inhibition of the prostaglandin-degrading enzyme 15-PGDH potentiates tissue regeneration. Science. 2015;348:aaa2340.

271. Antonova M, Wienecke T, Olesen J, Ashina M. Prostaglandins in migraine: update. Curr Opin Neurol. 2013;26:269-75.

272. Zhang XC, Strassman AM, Burstein R, Levy D. Sensitization and activation of intracranial meningeal nociceptors by mast cell mediators. J Pharmacol Exp Ther. 2007;322:806-12.

273. Harriott AM, Gold MS. Electrophysiological properties of dural afferents in the absence and presence of inflammatory mediators. J Neurophysiol. 2009;101:3126-34

274. Vaughn AH, Gold MS. Ionic mechanisms underlying inflammatory mediatorinduced sensitization of dural afferents. J Neurosci. 2010;30:7878-88.

275. Myren M, Baun M, Ploug KB, Jansen-Olesen I, Olesen J, Gupta S. Functional and molecular characterization of prostaglandin E2 dilatory receptors in the rat craniovascular system in relevance to migraine. Cephalalgia. 2010;30:1110-22.

276. Cairns BE, Laursen JC, Dong XD, Gazerani P. Intraganglionic injection of a nitric oxide donator induces afferent mechanical sensitization that is attenuated by palmitoylethanolamide. Cephalalgia. 2014;34:686-94.

\section{Publisher's Note}

Springer Nature remains neutral with regard to jurisdictional claims in published maps and institutional affiliations.

Ready to submit your research? Choose BMC and benefit from:

- fast, convenient online submission

- thorough peer review by experienced researchers in your field

- rapid publication on acceptance

- support for research data, including large and complex data types

- gold Open Access which fosters wider collaboration and increased citations

- maximum visibility for your research: over $100 \mathrm{M}$ website views per year

At $\mathrm{BMC}$, research is always in progress.

Learn more biomedcentral.com/submissions 